\title{
Bölgelere ve İllere Göre Türkiye Finansal Kapsayıcılık Endeksi*
}

\author{
Haşmet SARIGÜL**
}

\section{ÖZET}

Çalışmanın amacı finansal kapsayıcılı̆̆ın Türkiye'de 2011-2018 dönemindeki gelişiminin araştırllmasıdır. Bu kapsamda öncelikle dört finansal erişim ve üç finansal kullanım boyutu verileri kullantlarak Türkiye Finansal Kapsayıcılık Endeksi oluşturulmuştur. Uygulanan yöntem ile finansal kapsayıcılık boyutları değerleri sıfir ile bir arasında olacak şekilde standart hale getirilmiş ve ters Öklid uzaklık bağıntıları ile bölge ve il bazında nihai endeks ortaya çıkartılmıştır. Endeks oluşturulduktan sonra iller ve bölgeler finansal kapsayıcılık endeks değerlerine göre çok yüksek, yüksek, orta, düşük ve çok düşük olarak sınıflandırllmıştır. Incelenen yılların tamamında İstanbul'un çok yüksek; Batı Marmara, Ege ve Batı Anadolu'nun yüksek; Doğu Marmara, Akdeniz ve Doğu Karadeniz'in orta; Batı Karadeniz'in düşük; Kuzeydoğu Anadolu, Ortadoğu Anadolu ve Güneydoğu Anadolu'nun çok düşük finansal kapsayıcılık endeks değerlerine sahip oldukları görülmüşür. Orta Anadolu Bölgesinde 2011-2013 yılları arasında düşük, sonrasında orta düzey finansal kapsayıcılı söz konusudur. Kuzeydoğu Anadolu 2018 yılında düşük, diğer yıllarda çok düşük finansal kapsayıcılık düzeyindedir. Illerin finansal kapsayıcılık endeks değerleri genel olarak içerisinde yer aldıkları bölgeler ile uyumludur.

Anahtar Kelimeler: Finansal kapsayıcılık, Finansal erişim, Finansal kullanım, Endeks, Türkiye

JEL Sinıflandırması: G29, G59.

\section{An Index of Financial Inclusion by Regions and Provinces in Turkey}

\section{ABSTRACT}

The aim of the study is to investigate the development of financial inclusion in Turkey spanning the period 2011-2018. In this context, financial inclusion index of Turkey has been developed by using four financial access and three financial usage dimensions data. Each financial inclusion dimension data has been standardized from 0 to 1 range. Index values regions and provinces have been calculated by using inverse Euclidean distances. The financial inclusion findings of the research have been evaluated as very high, high, medium, low and very low according to the regions. It is revealed that; Istanbul has very high; Western Marmara, Aegean and Western Anatolia have high; Eastern Marmara, Mediterranean and Eastern Black Sea have medium; Western Black Sea have low; Middle East Anatolia and Southeast Anatolia have very low financial inclusion index values. The financial inclusion index values of the provinces are considerably consistent with the regional index values in which they are included.

Keywords: Financial inclusion, Financial access, Financial usage, Index, Turkey

Jel Classification: G29, G59.

\footnotetext{
* Makale Gönderim Tarihi: 07.02.2021, Makale Kabul Tarihi: 14.03.2021, Makale Türü: Nicel Araştırma

** Prof. Dr., İstanbul Esenyurt Üniversitesi, hasmetsar@yahoo.com, ORCID: 0000-0001-7262-6668.
} 


\section{GİRiş}

Finansal kapsayıcılık, finans literatüründe yaygın olarak tartışılan konulardan birisi olmasına karşın, çok boyutlu yapısı ve çeşitli farklı yaklaşımlar nedeniyle ortak bir tanıma sahip değildir. Bununla birlikte, bireylerin finansal hizmetlere etkin bir şekilde erişebileceği ve finansal ürünleri kullanabileceği duruma yönelik bir kavram olarak kabul görmektedir. Finansal kapsayıcılık genel olarak toplumun ekonomik açıdan zayıf ve dezavantajlı olarak kabul edilen bireylerinin finansal ürünlere erişmesine ve bunları kullanabilmesine olanak sağlayan bir finansal sistemin varlığı olarak tanımlanabilir. Finansal kapsayıcılık, finansal hizmetlerin ve ürünlerin toplumun çoğunluğu tarafından erişilebilir ve kullanılabilir durumda olmasını esas alırken, finansal dışlanma düşük gelirli ve dezavantajlı gruplardaki bireylerin finansal hizmetlere erişmesinin ve kullanabilmesinin önündeki engellere vurgu yapmaktadır (Sarıül, 2020: 223).

Finansal kapsayıcılık düzeyini etkileyen faktörler arz veya talep kaynaklı olabilir. Sosyo-ekonomik unsurlar ile bireylerin finansal konulara ilişkin algı ve tutumları arz yönlü faktörlerdir. Finansal hizmetlere yeterince ulaşılamaması veya bunların kullanılmasının önündeki engeller, diğer bir deyişle finansal dişlanma, gönüllü veya istemsiz olarak ortaya çıkabilir. Gönüllü finansal dişlanma, kültürel veya inanca dayalı faktörlerden veya bireylerin finansal hizmetlere karşı kişisel ilgisizliğinden kaynaklanabilir. İstemsiz dışlanma ise uygun olmayan fiyatlar ve oranlar, ihtiyaçlara cevap veremeyen ürün tasarımı ve diğer uygunluk ölçütlerini karşılayamama engellerini içerir. Talep taraflı faktörler arasında gelir, eğitim düzeyi, yaş, cinsiyet, ulaşım ve telekomünikasyon gibi çeşitli sosyo-ekonomik ve teknolojik faktörler yer almaktadır (Abel, Mutandwa ve Le Roux, 2018: 3; Demirguc-Kunt, Klapper, Singer ve Van Oudheusden, 2015: 10; European Commission, 2008: 94).

Ekonomik faktörler, finansal kapsayıcılığın temel belirleyicilerindendir. Birçok araştırma finansal kapsayıcılık ile ekonomik kalkınma arasında pozitif yönlü anlamlı ilişkili olduğunu; işsizlik, yoksulluk ve gelir eşitsizliği gibi faktörlerin finansal hizmetlere erişimi ve bunların kullanımını olumsuz etkilediğini ortaya koymaktadır (Bittencourt, 2012; Jeanneney ve Kpodar, 2011; Pal ve Vaidya, 2011; Clarke, Xu ve Zou 2006). Sosyo-demografik faktörler ise finansal kapsayıcılığın güçlendirilmesinde önemli bir rol oynamaktadır. Sosyodemografik faktörlerin finansal kapsayıcılığı desteklemediği toplumlarda, bireylerin finansal hizmetleri kullanmaktan kaçınma olasılığı daha yüksektir, daha az bireyin banka hesabı vardır ve nakit para ile gerçekleştirilen işlemler daha yaygındır. Bu durum finansal kapsayıcılığın talep yönünü etkilemektedir (Cull, Ehrbeck ve Holle, 2014; Dev, 2006). Finansal kapsayıcılık düzeyini etkileyen bir diğer faktör teknolojidir. Finansal hizmetler sektörü genel olarak teknolojik yenilikleri destekleyen ve bunları en hızlı uygulamaya koyanlardan birisidir. Yenilikçi finansal hizmetler şirketleri müşterilerinin günlük işlemlerini uygun maliyetli, daha kolay ve hızlı hale getirmek için dijital platformlar oluşturmakta ve geliştirmektedirler. Teknolojik gelişmeler finansal hizmetlere ulaşmak için uzun mesafeler kat etme zorunluluğunu azalmakta, finansal ürün ve hizmetlerin etkin ve verimli dağıtımını sağlamaktadır. Elektronik ödeme sistemleri, mobil bankacılık ve diğer finansal teknoloji uygulamaları giderek yaygınlaşmakta, finansal kapsayıcılık dijital dünyadan yeni ve geniş kapsamlı bir paydaş grubu ile gelişmektedir (Global Partnership for Financial Inclusion, 2014; De Koker ve Jentzsch, 2013; Duncombe ve Boateng, 2009). 
Finansal sistemler ve ekonomi üzerindeki olumlu etkileri nedeniyle finansal kapsayıcılık ile ilgili konular son dönemlerde araştırmacılar, politika yapıcılar ve uygulayıcılar arasında giderek daha fazla ilgi görmektedir. Birçok ülkede düşük gelirli ve dezavantajlı olarak kabul edilen grupların finansal sisteme daha fazla eklenmesini sağlayacak stratejiler geliştirmek için çalışmalar yürütülmektedir. Bu çabalar Uluslararası Para Fonu ve Dünya Bankası'nın da içinde olduğu çeşitli uluslararası kuruluşlar tarafindan da desteklenmektedir (Demirguc-Kunt, Beck ve Honohan, 2008; Leyshon ve Thrift, 1995). Türkiye'de de finansal erişim ve finansal altyapı göstergeleri dikkate alınarak finansal kapsayıcılığın talep yönünü güçlendirmek amacıyla 2014 yılında "Finansal Erişim, Finansal Eğitim, Tüketici Finansal Koruma Stratejisi ve Eylem Planları" uygulamaya konulmuştur (T.C. Başbakanlık, 2014). Bu kapsamda finansal tüketicinin korunması ve finansal eğitim konularında elli beş eylem planı belirlenmiş ve birçok kamu kurumu, özerk kurum ve sivil toplum kuruluşu işbirliği yapılacak birimler olarak tanımlanmıştır. Buna karşın Türkiye'de finansal kapsayıcılık ile ekonomik, sosyal, demografik ve diğer konular arasındaki ilişkiyi anlamaya ve politika yapıcılara veri sağlamaya yönelik yeterli sayıda akademik çalışma yapılmadığı gözlemlenmiştir. Çalışmanın ilk amacı finansal kapsayıcılık endeksi oluşturmak suretiyle bölgelerin ve illerin finansal kapsayıcılık düzeyleri ile gelişimlerini incelemek ve karşılaştırmaktır. Ayrıca finansal kapsayıcılık bileşenleri ile çeşitli sosyo-ekonomik ve teknolojik değişkenlerin arasındaki ilişkiyi ve finansal kapsayıcılık düzeyinin nedenleri ile etkilerini araştıracak bilimsel çalışmalara veri sağlanması ve böylece finansal kapsayıcılığın artırılmasına yönelik politikalar ile uygulamalar geliştirilmesine katkı sağlanması hedeflenmektedir.

Çalışmada giriş bölümünden sonra finansal kapsayıcılıkla ilgili literatür irdelenmiştir. Üçüncü bölümde veriler ve yöntem paylaşmıştır. Dördüncü bölümde Türkiye için bölgeler ve iller bazında oluşturulan finansal kapsayıcılık endeksine ait bulgular sunulmuştur. Son bölümde tartışma ve sonuçlar yer almaktadır.

\section{LITERATÜR}

Kalkınmanın farklı alanlara yayılması gerektiği varsayımından hareketle ilk olarak 1997 yılında İngiltere'de tartışılmaya başlanan finansal kapsayıcılık kavramı zaman içerisinde çeşitli ulusal ve uluslararası kurumların, araştırmacıların ve uygulayıcıların ilgisini çekmeye başlamıştır. Öncü çalışmalar daha çok finansal kapsayıcılığın tanımı ve niteliğine odaklanmaktadır (Dev, 2006). Daha sonra finansal kapsayıcılık ölçüm yöntemlerinin geliştirilmesi çalışmaları (Demirguc-Kunt, Klapper, Singer ve Van Oudheusden, 2015; Cámara ve Sali, 2014; Chakravarty ve Pal, 2013; Gupte, Venkataramani ve Gupta, 2012; Sarma, 2008; Kempson, Atkinson ve Pilley, 2004) ve farklı ülkelerde finansal kapsayıcılığın ölçülmesi, izlenmesi ve analiz edilmesine yönelik araştırmalar sıklaşmıştır (Gündüz ve Özyıldırım, 2019; Bayero, 2015; World Bank, 2014; Fungáčová ve Weill, 2015). Bu süreçte, finansal kapsayıcılık ile ekonomik, sosyal, demografik, coğrafi, teknolojik ve diğer değişkenler arasındaki ilişkiyi inceleyen çalışmalarla literatür genişlemiştir.

Literatürde en yoğun tartışılan konulardan birisi kalkınma ve ekonomik büyüme ile finansal kapsayıcılık düzeyi arasındaki ilişkidir. Raza, Tang, Rubab ve Wen (2019) Pakistan'da 2010-2015 yılları verileri ile gerçekleştirdikleri meta - analiz çalışmasında finansal kapsayıcılık düzeyindeki yükselmenin ekonomik kalkınmayı artırdığını belirlemişlerdir. Van, Vo, Nguyen ve Vo (2019) finansal kapsayıcılığın ekonomik büyüme 
üzerindeki etkisini tahmin etmek için bir panel ekonometrik model oluşturmuşlardır. Bulgular, önceki birçok çalışma ile tutarlı bir şekilde, ekonomik büyüme ile finansal kapsayıcılık arasında pozitif ilişki olduğunu desteklemektedir. Araştırmacılar buna ek olarak milli gelir ve finansal kapsayıcılık düzeylerinin düşük olduğu ülkelerde bu ilişkinin daha güçlü olduğunu belirlemişlerdir. Kim, Yu ve Hassan'ın (2018) İslam İşbirliği Örgütü'nün elli beş üye ülkesinin verilerini kullanarak yaptıkları panel veri çalışmasının sonuçları, finansal kapsayıcılığın ekonomik büyüme üzerinde olumlu etkisinin olduğunu göstermektedir. Sethi ve Sethy'nin (2018) 1975-2014 yılları arası Hindistan verileriyle gerçekleştirdikleri doğrusal modellere dayalı eşbütünleşme analizi çalışmasına göre ekonomik büyüme ile finansal kapsayıcılık arasında uzun dönemli anlamlı ilişki bulunmaktadır. Finansal kapsayıcılıktaki arz ve talep yönlü iyileşmeler ekonomik büyümeyi olumlu yönde etkilemektedir. Rastogi ve Ragabiruntha (2018) yapılandırılmış anket yöntemiyle topladıkları verileri kullanarak Tamil Nadu'da hangi finansal kapsayıcılık unsurlarının ekonomik kalkınmayı desteklediğini araştırmışlardır. Çalışmanın bulgularına göre; finansal okuryazarlık düzeyi, internet bankacılığı ve bankacılık hizmetleri finansal kapsayıcılığın itici güçleridir. Ekonomik büyüme ve finansal kapsayıcılık arasında pozitif ve uzun dönemli bir bağ olduğunu belirleyen bir başka çalışma, otuz bir ülkenin 2004-2011 dönemini kapsayan verileriyle Sethi ve Acharya (2018) tarafından gerçekleştirilmiştir.

Ekonomik refah göstergeleri ile finansal kapsayıcılık arasındaki araştırmalarda en fazla kullanılan değişkenler ise kişi başına GSYİH ve gelir eşitsizliğidir. Sha'bana, Girardone ve Sarkisyan'ın (2020) araştırma bulguları, kişi başına düşen GSYİH ile finansal kapsayıcılık arasında anlamlı ve pozitif ilişki olduğunu göstermektedir. Ginevicius, Dudzeviciute, Schieg ve Peleckis'e (2019) göre, kişi başına en yüksek GSYİH göstergelerine sahip ülkeler aynı zamanda en yüksek finansal kapsayıcılık düzeyine de sahiptirler. Nanda'ya (2017) göre, finansal kapsayıcılık düzeyi ile kişi başına gelir ve sosyo-ekonomik gelişmişlik birlikte ve aynı yönde hareket etmektedir. Sarma ve Pais'in (2011) araştırma sonuçları, kişi başına gayri safi yurtiçi hasıla, kentleşme, yetişkin okuryazarlığı ve gelir eşitsizliğinin bir ülkedeki finansal kapsayıcılık düzeyini açıklayan önemli faktörler olduğunu ortaya koymaktadır. Sani, Özdeşer ve Çavuşoğlu'nun (2019) Nijerya kırsal bölgelerine yönelik yapmış oldukları araştırmanın bulguları finansal kapsayıcılığın hane halkı refahı üzerinde güçlü ve olumlu etkisi olduğunu göstermektedir. Ayrıca artan finansal kapsayıcılık düzeyi orta ve yüksek gelirli hane halklarının düşük gelirli gelirlilere kıyasla bu durumdan daha fazla yararlanmalarını sağlamaktadır. Zhang ve Posso (2019) 6.200'den fazla Çin hane halkı verilerini kullanarak finansal kapsayıcılığın hane halkı geliri üzerindeki etkisini araştırmışlar ve finansal kapsayıcılığın hane halkı geliri üzerinde güçlü ve olumlu bir etkisi olduğunu bulmuşlardır. Nijerya'da yapılan Sani, Özdeşer ve Çavuşoğlu'nun çalışmalarının aksine, Zhang ve Pooso'nun Çin'deki araştırması düşük gelirli hane halklarının finansal kapsayıcılıktan orta ve yüksek gelir düzeyindeki hane halklarına göre daha fazla yararlandığını göstermektedir. Anwar ve Amrullah (2017) finansal kapsayıcılı̆̆ın genel ekonomiyi etkileyerek yoksulluğu azaltabileceğini, ancak aynı zamanda eşitsizliği de artırabileceğini belirtmiş̧lerdir. Kim (2016) OECD ve Avrupa Birliği'ndeki kırk ülkeye ait 2004-2011 dönemi verilerini kullandığ1 araştırma finansal kapsayıcılığın ekonomik büyüme ve gelir eşitsizliği arasındaki ilişkide iyileşmeye neden olduğunu ortaya koymaktadır. Bu etki yüksek ekonomik kırılganlığa sahip ülkelerde düşük kırılgan ekonomilere göre daha güçlüdür. 
Bilgi ve iletişim teknolojilerindeki gelişmelerin de finansal kapsayıcılı̆̆ın artırılmasında önemli faktörler olduğu kabul edilmektedir. Musabegovic, Özer, Djukovic ve Jovanovic (2019) yeni teknolojilerin kullanımı ile kişi başına düşen GSYİH arasındaki ilişkiyi araştırmışlar, kişi başına düşen GSYİH ile finansal işlemlerde ve ödeme süreçlerinde akıllı telefonların kullanımı arasında anlamlı ve pozitif bir ilişki olduğunu belirlemişlerdir. Patwardhan, Singleton ve Schmitz (2018) elektronik işlemlerin sağladığı kolaylıklardan yararlanmanın ve cep telefonlarını ödeme sistemlerine uyarlamanın maliyetleri düşürdüğünü ve finansal hizmetlere erişimi artırdığını ortaya koymuşlardır.

Literatürde finansal kapsayıcılığın yukarıda belirtilenler dışında farklı faktörlere dayalı olarak araştıran çalışmalar da mevcuttur. Dünya Bankası'nın 2017 Küresel Findex Veri tabanını kullanan Özsuca (2019) finansal ürün ve hizmetlerin kullanımında cinsiyet farklılıklarına neden olabilecek faktörleri araştırmıştır. Çalışmanın sonuçları finansal kapsayıcılık konusundaki eşitsizliğin istihdam ile önemli ölçüde ilişskili olduğunu göstermektedir. Yaş ve öğrenim düzeyi de finansal kapsayıcılık açığına katkıda bulunan faktörler arasındadır. Alhassan, Li, Reddy ve Duppati'nin (2019) araştırma bulguları, finansal kapsayıcılık düzeyinin yükseköğrenim ve yüksek gelir ile pozitif yönde ilişkili olduğunu ve işsizlikten olumsuz yönde etkilendiğini göstermektedir. Szopinski (2019), Polonya'da herhangi bir bankada hesabı olmayanları araştırmış ve bu duruma düşük gelir, düşük eğitim seviyeleri, genç yaş, ticari bankalara güven eksikliği ve kırsal bölgelerde yaşamanın etki ettiğini bulmuştur. Bozkurt, Karakuş ve Yıldız (2018), 120 ülkenin 2011-2014 dönemi verilerini kullanarak finansal kapsayıcılık seviyelerinde değişiklik yaratabilecek olası faktörleri incelemişlerdir. Çalışmanın sonuçları, finansal kapsayıcılık düzeyindeki değişimi en fazla etkileyen faktörlerin sosyal, politik ve bankacılık ile ilgili konular olduğunu ortaya koymuştur. Otuz OECD ülkesinin verilerini kullandıkları araştırmalarında Van der Werff, Hogarth ve Peach (2013) finansal kurumlara ve hükümete olan güvendeki artışın finansal kapsayıcılık düzeyinin yükselmesine neden olduğunu belirlemişlerdir.

Türkiye'de ise finansal kapsayıcılık ile ilgili gerçekleştirilen bilimsel çalışmalar oldukça sınırlıdır. Temizel ve Bayçelebi (2018) Eskişehir'de İktisadi ve İdari Bilimler Fakültesinde belirli finansal ürün ve hizmetlerin öğrenciler tarafından kullanılıp kullanılmama durumunu, eğer kullanılmıyorsa nedenlerinin araştırılmak için bir anket çalışması yapmışlardır. Sonuçlar öğrencilerin finansal dişlanmışlık düzeylerinin yüksek olduğunu ortaya koymuştur. Bir diğer çalışmada Seven, Yassa ve Yılmaz (2020) finansal kapsayıcılığın temel demografik göstergelerle ilişkisini analiz etmişlerdir. Bulgular 2010 yılından 2020 yılına kadar geçen dönemde dünya genelinde finansal kapsayıcılık düzeyinde önemli bir mesafe alındığını göstermektedir. Aynı gelir grubunda yer aldığı ülkelere göre Türkiye'nin finansal kapsayıcılık düzeyi daha yüksek olmasına karşın kadınların finansal sisteme katılım düzeyi benzer ülkeler ortalamasının oldukça altındadır. Diğer taraftan Türkiye'de finansal kapsayıcılık ile gelir ve eğitim seviyesi arasında pozitif ilişki bulunmaktadır. Finansal kapsayıcılık endeksi geliştirilmesine yönelik ise Türkiye'de iki çalışmaya rastlanmıştır. Bozkurt ve Karakuş (2020) illerin 2011-2016 dönemini kapsayan verilerini kullanarak bir endeks oluşturduktan sonra bunların finansal kapsayıcılık düzeylerini etkileyen itici güçleri araştırmışlardır. Bulgular, iller bazında finansal kapsayıcılığın belirleyicilerinin işsizlik, kentleşme, turizm, bireylerin medeni durumu, eğitim düzeyi, enflasyon ve suç değişkenleri olduğunu göstermiştir. Bozkurt ve Karakuş araştırmalarında finansal kullanım düzeyinin belirlenmesine yönelik olarak birisi "yetişkinler tarafından ibraz edilen toplam çek sayısı" 
olmak üzere dört gösterge kullanmışlardır. Çalışmamızda ise Türkiye'de keşide edilen çeklerin büyük çoğunlukla ticari ilişkilerden doğan işlemlere dayanıyor olması nedeniyle "yetişkinler tarafından ibraz edilen toplam çek sayısı" bireylere yönelik finansal kullanım göstergesi olarak dikkate alınmamıştır. Yorulmaz (2013) Türkiye'de bölgeler ve iller arasında karşılaştırma yapabilmesini mümkün kılabilmek için finansal kapsayıcılık endeksi geliştirmiştir. Yorulmaz çalışmasında ilgili dönem itibarıyla mevduat hesabı sayılarına ulaşılamadığı için mevduat hesaplarının hacmini finansal erişimin göstergelerinden birisi olarak dikkate alırken, çalışmamızda bireylerin mevduat hesaplarının bölge ve il bazındaki toplam sayıları esas alınmıştır.

\section{VERİ SETİ VE YÖNTEM}

Finansal kapsayıcılığın ölçülmesinde yaygın olarak kullanılan göstergeler finansal hizmetlere ve ürünlere erişim, bunların kullanımı ve kalitesi ile ilgili ölçütlerdir. Erişim göstergeleri finansal erişimin derinliğini yansıtır. Kullanım göstergeleri yetişkinlerin finansal hizmetleri nasıl kullandığını ölçmektedir. Kalite ölçütleri ise finansal ürün ve hizmetlerin müşterilerin ihtiyaçlarına uygunluk düzeyini, müşterilerin kullanabileceği seçeneklerin genişliğini, yetişkinlerin finansal hizmetler ve ürünler hakkındaki farkındalık düzeyini ve bunlara yönelik tutumlarını ortaya koymaktadır (World Bank, 2012).

$\mathrm{Bu}$ çalışmada, finansal kapsayıcılığın hesaplanmasında verilerine ulaşılabilen dört erişim ve üç kullanım göstergesi kullanılmıştır. Erişimle ilgili göstergeler, finansal hizmet merkezlerinin demografik ve coğrafi yayılımını göstermektedir. Kullanım göstergeleri ise finansal hizmet ile finansal ürün kullanımının yayınlığını ve uygunluğunu ortaya koymaktadır (Tablo 1).

Tablo 1. Araştırmada Kullanılan Finansal Kapsayıcılık Göstergeleri

\begin{tabular}{|c|c|c|c|}
\hline & Kod & Gösterge* & Açıklama \\
\hline \multirow{4}{*}{ 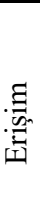 } & $S ̧ B D C$ & Şube dağılımı (coğrafi) & $1.000 \mathrm{~km}^{2}$ başına düşen şube sayısı. \\
\hline & $S ̧ B D D$ & Şube dağılımı (demografik) & 100.000 kişi (+15 yaş) başına düşen şube sayısı. \\
\hline & ATMC & ATM dağglımı (coğrafi) & 1.000 km² başına düşen ATM sayısı. \\
\hline & $A T M D$ & Şube dağılımı (demografik) & 100.000 kişi (+15 yaş) başına düşen ATM sayısı. \\
\hline \multirow{3}{*}{$\frac{\bar{\Xi}}{\stackrel{\Xi}{\Xi}}$} & KGOK & $\begin{array}{l}\text { Kredi / gelir oranı } \\
\text { (karş1lanabilirlik) }\end{array}$ & $\begin{array}{l}\text { Kişi (+15 yaş) başına düşen bireysel kredi tutarının kişi başına düşen } \\
\text { gayrisafi yurt içi hasılaya oranı. }\end{array}$ \\
\hline & $T M D Y$ & $\begin{array}{l}\text { Mevduat dağılımı } \\
\text { (yaygınlık) }\end{array}$ & 1.000 kişi ( +15 yaş) başına düşen tasarruf mevduatı sayısı. \\
\hline & GMOK & $\begin{array}{l}\text { Mevduat / gelir oranı } \\
\text { (karşılanabilirlik) }\end{array}$ & $\begin{array}{l}\text { Kişi ( }+15 \text { yaş) başına düşen tasarruf mevduatı tutarının kişi başına gayrisafi } \\
\text { yurt içi hasılaya oranı. }\end{array}$ \\
\hline
\end{tabular}

* Göstergelere ilişkin veriler birer açık kaynak olan Türkiye İstatistik Kurumu, Türkiye Bankalar Birliği, Türkiye Katılım Bankaları Birliği ve Türkiye Bankacılık Düzenleme ve Denetleme Kurumunun WEB sitelerinden sağlanmıştır. ATM: Otomatik para çekme ünitesi. 
$S ̧ B D C$ ve $A T M C$ finansal hizmetlere erişiminin coğrafi dağılımını, $S B D D$ ve $A T M D$ finansal hizmetlere erişimin demografik yayılımını ortaya koymaktadır. Bir banka şubesinin ve ATM'nin hizmet verdiği birey sayısı ile coğrafi alanı ölçen $S B D C$, $A T M C$, $S B D D$ ve $A T M D$ değerlerinin yüksekliği şube veya ATM başına daha az bireye hizmet verildiğine ve hizmet noktalarına erişimin göreli kolaylığına vurgu yapmaktadır. TMDY finansal hizmetlerin kullanımının yaygınlık göstergelerinden birisidir. $K G O K$ ve $G M O K$ finansal ürünlerin ortalama birey tarafindan karşılanabilme gücüne işaret etmektedir. Kişi baş̧ına düşen GSYH'ye kıyasla kredi ve mevduat tutarlarının çok yüksek olması bu ürünlerin üst gelir gruplarınca kullanılabildiğini, düşük gelir seviyesine sahip bireylerin bu ürünlerin kullanımına uzak olduğunu göstermektedir (Işık, 2011).

Tablo 2. Finansal Kapsayıcılık Göstergelerine Ait Tanımlayıcı İstatistikler

\begin{tabular}{|c|c|c|c|c|c|c|c|c|c|c|}
\hline & & & 2011 & 2012 & 2013 & 2014 & 2015 & 2016 & 2017 & 2018 \\
\hline \multirow{28}{*}{ 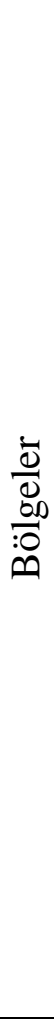 } & \multirow{4}{*}{ ŞBDC } & En Küçük & 2,39 & 2,46 & 2,66 & 2,74 & 2,80 & 2,72 & 2,84 & 2,96 \\
\hline & & En Büyük & 582,44 & 612,39 & 653,57 & 658,81 & 656,00 & 619,13 & 606,40 & 602,28 \\
\hline & & Ortalama & 59,67 & 62,79 & 67,25 & 67,95 & 67,84 & 64,22 & 63,04 & 62,73 \\
\hline & & Std.Sapma & 165 & 173,4 & 185 & 186,5 & 185,6 & 175,1 & 171,5 & 170,3 \\
\hline & \multirow{4}{*}{$S \beta B D D$} & En Küçük & 5,55 & 5,96 & 6,49 & 6,79 & 6,90 & 6,65 & 6,50 & 6,43 \\
\hline & & En Büyük & 22,84 & 23,77 & 25,77 & 25,72 & 25,98 & 24,61 & 23,98 & 23,76 \\
\hline & & Ortalama & 13,41 & 13,99 & 15,02 & 15,15 & 15,12 & 14,33 & 14,06 & 13,88 \\
\hline & & Std.Sapma & 5,91 & 6,08 & 6,40 & 6,27 & 6,18 & 5,73 & 5,47 & 5,40 \\
\hline & \multirow{4}{*}{ ATMC } & En Küçük & 6,66 & 6,93 & 8,38 & 9,23 & 9,86 & 10,09 & 10,70 & 10,65 \\
\hline & & En Büyük & $1.511,32$ & $1.685,94$ & $1.893,32$ & $2.025,45$ & $2.099,94$ & $2.100,88$ & $2.171,25$ & $2.212,80$ \\
\hline & & Ortalama & 159,30 & 177,03 & 199,88 & 214,73 & 223,52 & 224,86 & 232,33 & 236,51 \\
\hline & & Std.Sapma & 426,83 & 476,31 & 534,59 & 571,65 & 592,44 & 592,38 & 612,21 & 624,02 \\
\hline & \multirow{4}{*}{ ATMD } & En Küçük & 14,85 & 16,25 & 19,38 & 21,46 & 22,69 & 23,06 & 23,51 & 23,32 \\
\hline & & En Büyük & 78,69 & 85,94 & 98,36 & 103,41 & 108,40 & 110,63 & 112,57 & 112,34 \\
\hline & & Ortalama & 39,76 & 43,16 & 49,23 & 53,00 & 55,30 & 55,87 & 57,21 & 56,95 \\
\hline & & Std.Sapma & 19,44 & 21,41 & 23,72 & 24,53 & 25,27 & 25,51 & 25,79 & 25,95 \\
\hline & \multirow{4}{*}{$K G O K$} & En Küçük & 0,10 & 0,10 & 0,11 & 0,11 & 0,11 & 0,11 & 0,10 & 0,09 \\
\hline & & En Büyük & 0,18 & 0,19 & 0,20 & 0,19 & 0,19 & 0,19 & 0,18 & 0,16 \\
\hline & & Ortalama & 0,15 & 0,16 & 0,17 & 0,16 & 0,16 & 0,16 & 0,16 & 0,14 \\
\hline & & Std.Sapma & 0,03 & 0,03 & 0,03 & 0,03 & 0,03 & 0,03 & 0,02 & 0,02 \\
\hline & \multirow{4}{*}{$T M D Y$} & En Küçük & 760,26 & 781,54 & 840,81 & 898,17 & 918,21 & $1.010,29$ & $1.111,07$ & $1.232,73$ \\
\hline & & En Büyük & $2.148,20$ & $2.162,58$ & $2.280,61$ & $2.283,25$ & $2.357,33$ & $2.619,67$ & $2.800,39$ & $3.113,69$ \\
\hline & & Ortalama & $1.660,88$ & $1.662,87$ & $1.775,99$ & $1.817,49$ & $1.880,27$ & $2.022,83$ & $2.207,90$ & $2.401,43$ \\
\hline & & Std.Sapma & 462,12 & 450,46 & 472,22 & 470,41 & 485,17 & 516,71 & 559,49 & 603,25 \\
\hline & \multirow{4}{*}{$G M O K$} & En Küçük & 0,11 & 0,10 & 0,11 & 0,11 & 0,12 & 0,13 & 0,14 & 0,15 \\
\hline & & En Büyük & 0,52 & 0,49 & 0,53 & 0,53 & 0,56 & 0,60 & 0,58 & 0,62 \\
\hline & & Ortalama & 0,26 & 0,25 & 0,26 & 0,26 & 0,28 & 0,30 & 0,30 & 0,32 \\
\hline & & Std.Sapma & 0,13 & 0,12 & 0,13 & 0,13 & 0,14 & 0,15 & 0,14 & 0,15 \\
\hline \multirow{16}{*}{$\stackrel{\Xi}{\Xi}$} & \multirow{4}{*}{$S \beta B D C$} & En Küçük & 1,29 & 1,55 & 1,67 & 1,67 & 1,79 & 1,76 & 1,76 & 1,76 \\
\hline & & En Büyük & 582,44 & 612,39 & 653,57 & 658,81 & 656,00 & 619,13 & 606,40 & 602,28 \\
\hline & & Ortalama & 17,71 & 18,66 & 20,17 & 20,50 & 20,66 & 19,75 & 19,48 & 19,49 \\
\hline & & Std.Sapma & 66,97 & 70,41 & 75,15 & 75,75 & 75,47 & 71,26 & 69,81 & 69,35 \\
\hline & \multirow{4}{*}{ ŞBDD } & En Küçük & 2,89 & 3,39 & 3,39 & 3,89 & 4,16 & 4,43 & 4,63 & 4,58 \\
\hline & & En Büyük & 22,84 & 23,77 & 25,77 & 25,72 & 25,98 & 24,61 & 23,98 & 23,76 \\
\hline & & Ortalama & 10,88 & 11,32 & 12,23 & 12,42 & 12,50 & 11,89 & 11,76 & 11,58 \\
\hline & & Std.Sapma & 4,28 & 4,30 & 4,43 & 4,41 & 4,31 & 4,03 & 3,91 & 3,79 \\
\hline & \multirow{4}{*}{ ATMC } & En Küçük & 4,19 & 4,19 & 5,24 & 5,46 & 6,01 & 6,35 & 6,08 & 5,81 \\
\hline & & En Büyük & $1.511,32$ & $1.685,94$ & 1.893,32 & $2.025,45$ & $2.099,94$ & $2.100,88$ & $2.171,25$ & $2.212,80$ \\
\hline & & Ortalama & 51,68 & 57,39 & 65,99 & 71,53 & 75,15 & 76,73 & 79,61 & 80,46 \\
\hline & & Std.Sapma & 175,82 & 196,32 & 220,95 & 236,46 & 245,62 & 246,39 & 254,87 & 259,24 \\
\hline & \multirow{4}{*}{$A T M D$} & En Küçük & 10,13 & 10,50 & 13,06 & 14,10 & 15,38 & 16,08 & 16,31 & 16,70 \\
\hline & & En Büyük & 91,25 & 96,11 & 107,65 & 116,94 & 120,15 & 120,48 & 120,69 & 117,83 \\
\hline & & Ortalama & 31.94 & 34.63 & 39.97 & 43.37 & 45.46 & 46.09 & 47.30 & 46.79 \\
\hline & & Std.Sapma & 14.77 & 16.03 & 17.84 & 18.84 & 19.16 & 19.11 & 19.26 & 18.89 \\
\hline
\end{tabular}




\begin{tabular}{|c|c|c|c|c|c|c|c|c|c|}
\hline \multirow{4}{*}{$K G O K$} & En Küçük & 0,07 & 0,07 & 0,08 & 0,09 & 0,08 & 0,07 & 0,08 & 0,08 \\
\hline & En Büyük & 0,23 & 0,25 & 0,25 & 0,24 & 0,23 & 0,24 & 0,23 & 0,21 \\
\hline & Ortalama & 0,15 & 0,16 & 0,17 & 0,17 & 0,16 & 0,16 & 0,16 & 0,14 \\
\hline & Std.Sapma & 0,03 & 0,04 & 0,04 & 0,03 & 0,03 & 0,03 & 0,03 & 0,03 \\
\hline \multirow{3}{*}{$T M D Y$} & En Küçük & 567,43 & 576,04 & 612,10 & 625,75 & 654,22 & 710,51 & 784,55 & 881,37 \\
\hline & En Büyük & $2.807,43$ & $2.671,59$ & $2.719,61$ & 2.691,37 & 2,769.27 & 2,897.83 & $3,195.74$ & $3,471.37$ \\
\hline & Ortalama & $1,582.78$ & $1,589.23$ & $1,700.83$ & $1,756.28$ & $1,791.33$ & $1,917.92$ & $2,110.47$ & $2,287.93$ \\
\hline \multirow{3}{*}{ GMOK } & En Büyük & 0,52 & 0,49 & 0,53 & 0,53 & 0,56 & 0,60 & 0,58 & 0,62 \\
\hline & Ortalama & 0,20 & 0,20 & 0,20 & 0,21 & 0,22 & 0,23 & 0,24 & 0,25 \\
\hline & Std.Sapma & 0,10 & 0,10 & 0,11 & 0,10 & 0,11 & 0,11 & 0,11 & 0,12 \\
\hline
\end{tabular}

Finansal kapsayıcılık göstergelerin ayrı yorumlanması yanıltıcı sonuçlara yol açabilecektir. Bu nedenle tek bir değer olarak bilgi sağlamak ve sonraki çalışmalarda sayısız değişkenle ilişkisinin ölçülmesini mümkün kılabilmek amacıyla Türkiye için illere ve bölgelere göre Finansal Kapsayıcılık Endeksi (TFKE) oluşturulmuştur. TFKE'nin hesaplanmasında Dünya Bankası (Demirguc-Kunt, Klapper, Singer, Ansar ve Jake, 2018) ile Sarma (2008) ve Yorulmazın (2013) finansal kapsayıcıllk endeksi bileşenlerinden hareket edilmiștir. Ancak iller ve bölgeler bazında finansal teknoloji verileri ile finansal kurumlarca kullandırılan bireysel kredi sayılarına il bazında ulaşılamaması nedeniyle ilgili göstergeler endekse dâhil edilememiştir. Bölgelerin belirlenmesinde TUiK' in "İstatistikî Bölge Birimleri Sınıflandırması" (İBBS) esas alınmıştır (Tablo 2).

Tablo 3. TUIK İstatistikî Bölge Birimleri Sınıflandırması

\begin{tabular}{ll}
\hline Bölge & İler \\
\hline TR1 - İstanbul & İstanbul \\
\hline TR2 - Batı Marmara & Balıkesir, Çanakkale, Edirne, Kırklareli, Tekirdağ \\
\hline TR3 - Ege & Afyon, Aydın, Denizli, İzmir, Kütahya, Manisa, Muğla, Uşak \\
\hline TR4 - Doğu Marmara & Bursa, Eskişehir, Bilecik, Kocaeli, Sakarya, Düzce, Bolu, Yalova \\
\hline TR5 -Batı Anadolu & Ankara, Konya, Karaman \\
\hline TR6 - Akdeniz & Adana, Antalya, Burdur, Hatay, Isparta, Mersin (İçel), Kahramanmaraş, \\
\hline TR7 - Orta Anadolu & Osmaniye \\
\hline TR8 - Batı Karadeniz & Kırıkale, Aksaray, Niğde, Nevşehir, Kırşehir, Kayseri, Sivas, Yozgat \\
& Zonguldak, Karabük, Bartın, Kastamonu, Çankırı, Sinop, Samsun, \\
\hline TR9 - Doğu Karadeniz & Tokat, Çorum, \\
\hline TRA - Kuzeydoğu Anadolu & Amasya \\
\hline TRB - Ortadoğu Anadolu & Trabzon, Ordu, Giresun, Rize, Artvin, Gümüşhane \\
\hline TRC - Güneydoğu Anadolu & Erzurum, Erzincan, Bayburt, Ağrı, Kars, Iğdır, Ardahan \\
\hline & Malatya, Elâzı̆g, Bingöl, Tunceli, Van, Muş, Bitlis, Hakkâri \\
\hline Kaynak: Türogar, Mardin, Batman,
\end{tabular}

Kaynak: Türkiye İstatistik Kurumu 
TFKE oluşturulurken öncelikle finansal kapsayıcılığın her bir boyutu için iller veya bölgeler bazında bağımsız endeks değerleri hesaplanmıştır.

$$
b_{i}=\frac{g_{i}-\min _{i}}{\max _{i}-\min _{i}}
$$

$\left(b_{i}\right.$ : ilgili ilin veya bölgenin $i$ finansal kapsayıcılık boyutu için endeks değeri, $g_{\mathrm{i}}$ : ilgili ilin veya bölgenin $i$ finansal kapsayıcılık boyutu için gerçek değeri, $\min _{i}$ : $i$ boyutundaki en küçük değer, $\max _{\mathfrak{i}}$ : $i$ boyutundaki en büyük değer).

Uygulanan yöntem ile her bir finansal kapsayıcılık boyutu değeri sıfır ile bir arasında oluşturulmuş $\left(0 \leq b_{i} \leq 1\right)$ ve standart hale getirilmiş olacaktır. Boyut değerinin yüksek olması ilgili ilin veya bölgenin finansal kapsayıcılık seviyesinin de yüksek olduğunu göstermektedir. Finansal kapsayıcılık endeksi hesaplamasında kullanılan boyut adedinin yedi olduğu göz önüne alındığında bir bölge veya il yıl bazında $y=\left(b 1_{i, t}, b 2_{i, t}, b 3_{i, t}, b 4_{i, t}, b 5_{i, t}, b 6_{i, t}, b 7_{i, t}\right)$ noktası ile temsil edilecektir. $y=(0,0,0,0,0,0,0)$ noktası en kötü durumu gösterirken $y=(1,1,1,1,1,1,1)$ bir ilin veya bölgenin alabileceği en yüksek finansal kapsayıcılık değerini ifade etmektedir (Sarma, 2008).

Her bir boyut için illere ve bölgelere göre veriler standart hale getirildikten sonra ters Öklid uzaklık bağıntıları ile $T K F E_{i, t}$ (i ilinin veya bölgesinin $t$ dönemindeki finansal kapsayıcılık endeks değeri) hesaplanmıştır (Yorulmaz, 2013; Sarma, 2008).

$$
T F K E_{i, t} \sqrt{\frac{\left(1-b 1_{i, t}\right)^{2}+\left(1-b 2_{i, t}\right)^{2}+\left(1-b 3_{i, t}\right)^{2}+\left(1-b 4_{i, t}\right)^{2}+\left(1-b 5_{i, t}\right)^{2}+\left(1-b 6_{i, t}\right)^{2}+\left(1-b 7_{i, t}\right)^{2}}{7}}
$$

TFKE oluşturulduktan sonra iller ve bölgeler finansal kapsayıcılık endeks değerlerine göre aşağıda gösterildiği gibi çok yüksek, yüksek, orta, düşük ve çok düşük olarak sinıflandırılmıştır.

- $\quad$ Çok yüksek finansal kapsayıcılık: $\left[\bar{x}_{t}+\frac{1-\bar{x}_{t}}{5} \times 3\right] \leq T K F E_{i, t} \leq 1$

- $\quad$ üksek finansal kapsayıcıl1k: $\left[\bar{x}_{t}+\frac{1-\bar{x}_{t}}{5}\right] \leq T K F E_{i, t}<\left[\bar{x}_{t}+\frac{1-\bar{x}_{t}}{5} \times 3\right]$

- $\quad$ Orta düzey finansal kapsayıc1lı: $\left[\bar{x}_{t}-\frac{\bar{x}_{t}}{5}\right] \leq T K F E_{i, t}<\left[\bar{x}_{t}+\frac{1-\overline{x_{t}}}{5}\right]$

- Düşük finansal kapsayıcılık: $\left[\bar{x}_{t}-\frac{\bar{x}_{t}}{5} \times 3\right] \leq T K F E_{i, t}<\left[\bar{x}_{t}-\frac{\bar{x}_{t}}{5}\right]$

- $\quad$ Çok düşük finansal kapsayıcılık: $0 \leq T K F E_{i, t} T K F E_{i, t}<\left[\bar{x}_{t}-\frac{\bar{x}_{t}}{5} \times 3\right]$

( $\bar{x}_{\mathbb{t}}:$ İllerin veya bölgelerin $t$ yılındaki endeks değerlerinin aritmetik ortalaması)

\section{BULGULAR}

Araştırmanın bulguları finansal kapsayıcılığın en yüksek olduğu bölgenin 2011-2018 arasındaki tüm yıllarda İstanbul olduğunu ortaya koymaktadır. En düşük finansal göstergelere 
sahip bölgeler ise Kuzeydoğu Anadolu, Ortadoğu Anadolu ve Güneydoğu Anadolu'dur (Tablo 4).

Tablo 4. Bölgelere Göre TFKE

\begin{tabular}{llcccccccc}
\hline Bölge & & 2011 & 2012 & 2013 & 2014 & 2015 & 2016 & 2017 & 2018 \\
\hline TR1 & İstanbul & 0,87 & 0,86 & 0,85 & 0,86 & 0,82 & 0,77 & 0,76 & 0,76 \\
TR2 & Bat1 Marmara & 0,52 & 0,53 & 0,54 & 0,54 & 0,55 & 0,54 & 0,55 & 0,55 \\
TR3 & Ege & 0,51 & 0,51 & 0,50 & 0,51 & 0,51 & 0,50 & 0,50 & 0,50 \\
TR4 & Doğu Marmara & 0,33 & 0,33 & 0,33 & 0,34 & 0,34 & 0,33 & 0,33 & 0,33 \\
TR5 & Bat1 Anadolu & 0,55 & 0,54 & 0,53 & 0,53 & 0,53 & 0,52 & 0,52 & 0,52 \\
TR6 & Akdeniz & 0,39 & 0,39 & 0,39 & 0,40 & 0,39 & 0,38 & 0,39 & 0,38 \\
TR7 & Orta Anadolu & 0,26 & 0,27 & 0,27 & 0,28 & 0,28 & 0,28 & 0,29 & 0,29 \\
TR8 & Bat1 Karadeniz & 0,26 & 0,26 & 0,26 & 0,26 & 0,26 & 0,24 & 0,24 & 0,24 \\
TR9 & Doğu Karadeniz & 0,32 & 0,32 & 0,31 & 0,32 & 0,31 & 0,31 & 0,32 & 0,31 \\
TRA & Kuzeydoğu Anadolu & 0,12 & 0,11 & 0,13 & 0,13 & 0,13 & 0,12 & 0,14 & 0,14 \\
TRB & Ortadoğu Anadolu & 0,08 & 0,06 & 0,07 & 0,09 & 0,09 & 0,09 & 0,10 & 0,11 \\
TRC & Güneydoğu Anadolu & 0,06 & 0,07 & 0,07 & 0,07 & 0,07 & 0,07 & 0,08 & 0,08 \\
\hline
\end{tabular}

Sonraki aşamada bölgelerin finansal kapsayıcılık düzeyleri Tablo 4'de sunulan endeks değerleri esas alınmak suretiyle çok düşük, düşük, orta, yüksek ve çok yüksek olarak sınıflandırılmıştır.

Tablo. 5 Bölgelerin TFKE Düzeylerinin Belirlenmesinde Esas Alınan Endeks Değerleri

\begin{tabular}{llllll}
\hline 2011 & $0,000 \leq d 5<0,142$ & $0,142 \leq d 4<0,284$ & $0,284 \leq d 3<0,484$ & $0,484 \leq d 2<0,742$ & $0,742 \leq d 1 \leq 1$ \\
2012 & $0,000 \leq d 5<0,142$ & $0,142 \leq d 4<0,283$ & $0,283 \leq d 3<0,483$ & $0,483 \leq d 2<0,742$ & $0,742 \leq d 1 \leq 1$ \\
2013 & $0,000 \leq d 5<0,142$ & $0,142 \leq d 4<0,284$ & $0,284 \leq d 3<0,484$ & $0,484 \leq d 2<0,742$ & $0,742 \leq d 1 \leq 1$ \\
2014 & $0,000 \leq d 5<0,144$ & $0,144 \leq d 4<0,288$ & $0,288 \leq d 3<0,488$ & $0,488 \leq d 2<0,744$ & $0,744 \leq d 1 \leq 1$ \\
2015 & $0,000 \leq d 5<0,142$ & $0,142 \leq d 4<0,285$ & $0,285 \leq d 3<0,485$ & $0,485 \leq d 2<0,742$ & $0,742 \leq d 1 \leq 1$ \\
2016 & $0,000 \leq d 5<0,139$ & $0,139 \leq d 4<0,277$ & $0,277 \leq d 3<0,477$ & $0,477 \leq d 2<0,739$ & $0,739 \leq d 1 \leq 1$ \\
2017 & $0,000 \leq d 5<0,140$ & $0,140 \leq d 4<0,281$ & $0,281 \leq d 3<0,481$ & $0,481 \leq d 2<0,740$ & $0,740 \leq d 1 \leq 1$ \\
2018 & $0,000 \leq d 5<0,140$ & $0,140 \leq d 4<0,280$ & $0,280 \leq d 3<0,480$ & $0,480 \leq d 2<0,740$ & $0,740 \leq d 1 \leq 1$ \\
\hline
\end{tabular}

$d 5$ : çok düşük, $d 4$ : düşük, $d 3$ : orta, $d 2$ : yüksek, $d 1$ : çok yüksek düzeyde finansal kapsayıcılığı göstermektedir.

Orta Anadolu ve Kuzeydoğu Anadolu Bölgesi dışındakilerin 2011-2018 yılları arasında yer aldığı sınıfta değişiklik olmadığı anlaşılmaktadır. Çok yüksek finansal kapsayıcılık değerlerine sahip tek bölge İstanbul, yüksek düzey finansal kapsayıcılığın olduğu bölgeler Batı Marmara, Ege ve Batı Anadolu’dur. 2011-2018 dönemindeki tüm y1llarda Doğu Marmara, Akdeniz ve Doğu Karadeniz orta düzey finansal kapsayıcılık endeks değerlerine sahiptirler. İlgili dönemin tamamında düşük finansal kapsayıcılık endeks değeri olan tek bölge 
Batı Karadeniz'dir. Orta Anadolu Bölgesinde ise 2011-2013 yılları arasında düşük, sonrasında orta düzey finansal kapsayıcılık söz konusudur. Ortadoğu Anadolu ve Güneydoğu Anadolu bölgeleri ilgili dönemin tamamında çok düşük finansal kapsayıcılık endeks değerlerine sahiptirler. Kuzeydoğu Anadolu 2018 yılında düşük, diğer yıllarda çok düşük finansal kapsayıcılık düzeyindedir. (Tablo 4).

Tablo 6. Bölgelerin Finansal Kapsayıcılık Düzeyleri

\begin{tabular}{lllllllllll}
\hline Bölge & İstanbul & 2011 & 2012 & 2013 & 2014 & 2015 & 2016 & 2017 & 2018 \\
\hline TR1 & $d 1$ & $d 1$ & $d 1$ & $d 1$ & $d 1$ & $d 1$ & $d 1$ & $d 1$ \\
TR2 & Batı Marmara & $d 2$ & $d 2$ & $d 2$ & $d 2$ & $d 2$ & $d 2$ & $d 2$ & $d 2$ \\
TR3 & Ege & $d 2$ & $d 2$ & $d 2$ & $d 2$ & $d 2$ & $d 2$ & $d 2$ & $d 2$ \\
TR4 & Doğu Marmara & $d 3$ & $d 3$ & $d 3$ & $d 3$ & $d 3$ & $d 3$ & $d 3$ & $d 3$ \\
TR5 & Bat1 Anadolu & $d 2$ & $d 2$ & $d 2$ & $d 2$ & $d 2$ & $d 2$ & $d 2$ & $d 2$ \\
TR6 & Akdeniz & $d 3$ & $d 3$ & $d 3$ & $d 3$ & $d 3$ & $d 3$ & $d 3$ & $d 3$ \\
TR7 & Orta Anadolu & $d 4$ & $d 4$ & $d 4$ & $d 3$ & $d 3$ & $d 3$ & $d 3$ & $d 3$ \\
TR8 & Bat1 Karadeniz & $d 4$ & $d 4$ & $d 4$ & $d 4$ & $d 4$ & $d 4$ & $d 4$ & $d 4$ \\
TR9 & Doğu Karadeniz & $d 3$ & $d 3$ & $d 3$ & $d 3$ & $d 3$ & $d 3$ & $d 3$ & $d 3$ \\
TRA & Kuzeydoğu Anadolu & $d 5$ & $d 5$ & $d 5$ & $d 5$ & $d 5$ & $d 5$ & $d 5$ & $d 4$ \\
TRB & Ortadoğu Anadolu & $d 5$ & $d 5$ & $d 5$ & $d 5$ & $d 5$ & $d 5$ & $d 5$ & $d 5$ \\
TRC & Güneydoğu Anadolu & $d 5$ & $d 5$ & $d 5$ & $d 5$ & $d 5$ & $d 5$ & $d 5$ & $d 5$ \\
\hline
\end{tabular}

$d 5$ : çok düşük, $d 4$ : düşük, $d 3$ : orta, $d 2$ : yüksek, $d 1$ : çok yüksek düzeyde finansal kapsayıcıllğı göstermektedir.

En yüksek endeks değerleri İstanbul Bölgesinde olmasına karşın ilgili bölgedeki finansal kapsayıcılığın gelişimi 2014 yılından itibaren düşme eğilimi göstermektedir (Grafik 1). 2011 yılından 2018 yılına kadar geçen dönemde Kuzeydoğu Anadolu'da \%120,74, Ortadoğu Anadolu'da \% 140,96 ve Güneydoğu Anadolu'da \% 128,65 düzeyinde iyileşme olduğu hesaplanmıştır. Diğer bölgelerde dikkati çeken oransal değişim gözlemlenmemiştir.

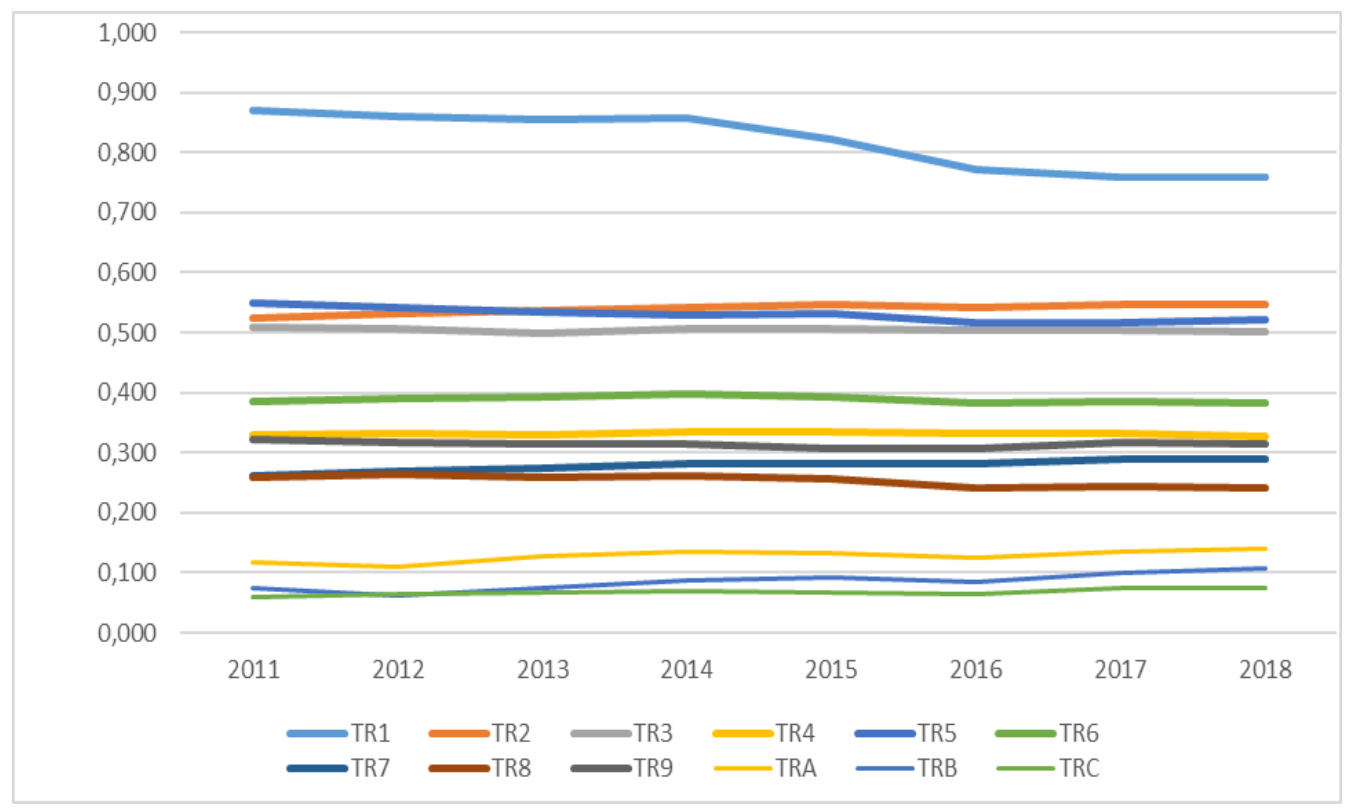

Grafik 1. Y1llara ve Bölgelere Göre TFKE Gelişimi 
Bölgelere göre finansal kapsayıcılığın hesaplanması önemli olmakla birlikte özellikle uç noktalarda yer alacak maksimum - minimum değerler endeksi etkileyebilecek ve illerin finansal kapsayıcılık düzeyi üzerindeki etkilerini tam olarak yansıtmayabilecektir. $\mathrm{Bu}$ kapsamda Türkiye'de finansal kapsayıcılığın daha detaylı değerlendirilebilmesi amacıyla illere göre de endeks oluşturulmuştur (Ek 1).

İllerin TFKE düzeylerinin belirlenmesinde esas alınan değerlere göre (Ek 2) İstanbul incelenen tüm yıllarda çok yüksek finansal kapsayıcılık düzeyindedir. Ankara, Antalya, İzmir ve Muğla ilgili dönemde yüksek finansal kapsayıcılık endeks değerlerine sahiptirler. Aydın ili 2015 y1lına kadar orta düzey, bu yıldan itibaren yüksek finansal kapsayıcılık endeks değerleri taşımaktadır. 2011-2018 dönemindeki tüm yıllarda orta düzey finansal kapsayıcılık endeks değeri hesaplanan il sayısı kırk dokuzdur (Afyonkarahisar, Aksaray, Amasya, Artvin, Balıkesir, Bartın, Bilecik, Bolu, Burdur, Bursa, Çanakkale, Çankırı, Çorum, Denizli, Düzce, Edirne, Erzincan, Eskişehir, Giresun, Hatay, Isparta, Karabük, Karaman, Kastamonu, Kayseri, Kırıkkale, Kırklareli, Kırşehir, Kocaeli, Konya, Kütahya, Malatya, Manisa, Mersin, Nevşehir, Ordu, Rize, Sakarya, Samsun, Sinop, Sivas, Tekirdağ, Tokat, Trabzon, Tunceli, Uşak, Yalova, Yozgat, Zonguldak). Bayburt 2016'da düşük, bunun dişındaki tüm yıllarda orta düzey, Ardahan ise 2011 ve 2012 y1llarında düşük takip eden yıllarda orta düzey finansal kapsayıcılık endeks değerlerine sahiptir. İlgili dönem boyunca düşük finansal kapsayıcılık düzeyinde olan on iki il olduğu görülmektedir. Bunlardan ikisi Akdeniz (Kahramanmaraş, Osmaniye), biri Orta Anadolu (Niğde), biri Doğu Karadeniz (Gümüşhane) üçü Kuzeydoğu Anadolu (Erzurum, Iğdır, Kars), biri Ortadoğu Anadolu (Elâzığ) ve dördü Güneydoğu Anadolu bölgesinde (Adıyaman, Diyarbakır, Gaziantep, Kilis) yer almaktadır. Çok düşük endeks değeri hesaplanan on bir ilin (Ağrı, Batman, Bingöl, Bitlis, Hakkâri, Mardin, Muş, Siirt, Şanlıurfa, Şırnak, Van) hiçbirinin finansal kapsayıcılık düzeylerinde araştırılan 20112018 dönemi süresince bir değişiklik olmamıştır. Bunların tamamı bölgesel olarak da çok düşük finansal kapsayıcılığa sahip olan Kuzeydoğu Anadolu, Ortadoğu Anadolu ve Güneydoğu Anadolu bölgelerinde bulunan illerdir (Ek 3).

\section{TARTIŞMA VE SONUÇ}

Finansal kapsayıcılık özellikle düşük gelirli ve dezavantajlı gruplarındaki bireylerin temel finansal hizmetlere erişmelerini ve bunlarının kullanımı sağlayan bir süreç olarak kabul edilmektedir. Bu kapsamda finansal kapsayıcılığın amaçlarını; dışlanmış grupların finansal sisteme dâhil edilmesi, düşük gelirli gruplar, mikro, küçük ve orta ölçekli işletmeler için uygun bankacılık hizmetleri sağlanması, kaynakların etkin dağılımının kolaylaştırılması olarak özetlemek mümkündür. Bir ülkede finansal kapsayıcılık düzeyinin yükselmesinin ülke ekonomisinin daha hızlı ve sağlıklı büyümesi, enflasyonun kontrol altına alınması, yoksulluğun azaltılması, istihdamın ve bireylerin kişisel refahlarının artması, finansal istikrarın sağlanması ve finansal sistemin şoklara dirençli hale gelmesi gibi konularda olumlu etkilerinin olması beklenir.

Sosyal ve ekonomik etkilerinin araştırılabilmesi için finansal kapsayıcılığın öncelikle ölçülebilmesi gereklidir. Buna karşın bir ülkenin veya bölgenin finansal kapsayıcılık düzeyini ölçmek veya değerlendirmek için tek ve tutarlı bir yöntem bulunmamaktadır. Diğer taraftan bir finansal sistemin ne kadar kapsayıcı olduğunu değerlendirmek için uygun bir ölçme aracı geliştirmeye yönelik çok sayıda çalışma yapılmıştır. Bu çalışmalarda daha çok finnansal erişim ve kullanım boyutlarının ön plana çıktığı görülmektedir. Son dönemlerde kullanılmaya 
başlanan bir diğer boyut finansal teknoloji göstergeleridir. Çalışmada Türkiye'de bölgelere ve illere göre finansal kapsayıcılık endeksi oluşturulurken yaygın olarak kullanılan finansal erişim göstergelerinin tamamı hesaplamalara dâhil edilmiş, finansal kapsayıcılık göstergelerinden verilerine il bazında ulaşılamayan biri dışındakiler dikkate alınmıştır. Finansal teknoloji verilerine ise ulaşılamaması nedeniyle hesaplamalarda kullanılamamıştır.

Araştırmanın finansal kapsayıcılık bulguları bölgeler göre çok yüksek, yüksek, orta, düşük ve çok düşük olarak değerlendirildiğinde tüm yıllarda İstanbul çok yüksek; Batı Marmara, Ege ve Batı Anadolu yüksek; Doğu Marmara, Akdeniz ve Doğu Karadeniz orta; Batı Karadeniz düşük, Ortadoğu Anadolu ve Güneydoğu Anadolu çok düşük endeks değerlerine sahiptir. Orta Anadolu Bölgesinde 2011-2013 yılları arasında düşük, sonrasında orta düzey finansal kapsayıcılık söz konusudur. Kuzeydoğu Anadolu ise 2018 yılında düşük, diğer yıllarda çok düşük finansal kapsayıcılık düzeyindedir. İllerin finansal kapsayıcılık endeks değerleri genel olarak içerisinde bulundukları bölge ile uyumludur.

Finansal kapsayıcılık endeksi verileri yorumlanırken bölgenin özelliklerinin de dikkate alınması gerekmektedir. Kentleşme, yerleşim merkezlerinin birbirlerine uzaklıkları, ulaşım ve haberleşme olanakları gibi faktörler finansal erişim göstergelerinin üzerinde etkilidir. $\mathrm{Bu}$ açıdan dezavantajlı olan bölgelerin finansal kapsayıcılık düzeylerinin diğerlerinden düşük olması beklenen bir durum olacaktır. Finansal erişim göstergeleri üzerinde etkili olan bir diğer unsur bölgenin demografik yapısıdır. Bölgenin nüfus artış (azalış) hızı ve nüfusun yaş yapısı makroekonomik değişkenler üzerinde etkili olabilmektedir. Yaş yapısının değişmesine paralel olarak nüfusun içerisindeki bağımlı ve çalışan bireylerin oranı da değişmektedir ve finansal ihtiyaçlar farklılaşmaktadır. Bir diğer ifadeyle ekonomik davranışları birbirinden farklı olan nüfus yapılarına sahip olan bölgelerin finansal erişim göstergeleri de farklı olabilecektir. Çeşitli faktörlerden etkilenen ekonomik yapı da finansal kurumların ilgili bölgeye yaklaşımları üzerinde etkilidir. Finansal kurumların, özellikle de ticari bankaların ülke genelindeki dağılımı iller arasındaki gelişmişlik farklarına bağlı olarak değişkenlik göstermekte, bu da illerin ve bölgelerin finansal kapsayıcılık düzeylerini etkilemektedir.

Araştırmanın kapsamı tüm finansal kapsayıcılık verilerine, özellikle de gelecekteki araştırmalarda daha yaygın olarak kullanılması beklenen finansal teknoloji göstergelerine ulaşılamaması nedeniyle sınırlıdır. Buna karşın oluşturulan endeks finansal kapsayıcılığın çeşitli faktörlerle ilişkisini araştırılabilmesi için önemli sayılabilecek veriler sağlamaktadır. İleriki dönemlerde illerin ve bölgelerin finansal kapsayıcılık endeks değerleri ile çeşitli sosyoekonomik ve teknolojik değişkenlerin ilişkisinin araştırılması ve finansal kapsayıcılığın nedenleri ile sonuçlarının analiz edilmesi faydalı olacaktır. Diğer taraftan literatürde yer alan çalışmaların sonuçları dikkate alındığında özellikle dezavantajlı gruplara yönelik finansal kapsayıcılık düzeyinin yükseltilmesine yönelik çalışmaların artırılması gerektiği görülmektedir. Bu kapsamda, finans sektöründe faaliyet gösteren başta bankalar olmak üzere tüm finansal hizmet sağlayıcıların bu hizmetlerin sunumunu kolaylaştırmak için bilgi sistemlerini ve organizasyonlarını güçlendirip genişletmeleri, finansal katılımı sağlamak veya artırmak için tüm eğitim ve öğretim düzeylerinde finansal eğitim programlarına yer verilerek finansal okuryazarlık düzeyinin artırılması, finansal konulardaki düzenlemelerin toplumun tamamını kapsayacak şekilde ele alınması, finansal düzenleme ve uygulamaların teknolojinin getirdiği olanaklardan en yüksek derecede faydalanacak şekilde geliştirilmesi ve uyarlanması faydalı olacaktır. 


\section{KAYNAKLAR}

Abel, Sanderson - Mutandwa, Learnmore - Le Roux, Pierre (2018), “A Review of Determinants of Financial Inclusion”, International Journal of Economics and Financial Issues, 8, 3, pp.1-8.

Alhassan, Abidin - Li, Leon - Reddy, Krishna - Duppati, Geeta (2019), “'The Relationship Between Political Instability and Financial Inclusion: Evidence from Middle East and North Africa', International Journal of Finance and Economics, Early Access, pp.122.

Anwar, Anas I. - Amrullah, Amiruddin (2017), “Impact of Financial Inclusion towards Poverty in Indonesia', Proceedings of the 2nd International Conference on Accounting, Management, and Economics, 40, pp.407-410.

Bittencourt, Manoel (2012), "Financial Development and Economic Growth in Latin America: Is Schumpeter Right?’, Journal of Policy Modeling, 34, 3, pp.341-355.

Bozkurt, İbrahim - Karakuş, Rifat (2020), "Provincial Financial Inclusion in Turkey: Measurement and Its Spatial Determinants”, Ege Academic Review, 20, 2, pp.101124.

Bozkurt, İbrahim, Karakuş, Rifat - Y1ldız, Melek (2018), “'Spatial Determinants of Financial Inclusion Over Time’, Journal of International Development, 30, pp.1474-1504.

Chakravarty, Satya R. - Pal, Rupayan (2013), “Financial Inclusion in India: An Axiomatic Approach’, Journal of Policy Modeling, 35, 5, pp.813-837.

Clarke, George - Xu, Lixin - Zou, Heng-Fu (2006), “Finance and Income Inequality: What Does the Data Tell Us?’’, Southern Economic Journal, 72, 3, pp.578-596.

Cull, Robert - Ehrbeck, Tilman - Holle, Nina (2014), “Financial Inclusion and Development: Recent Impact Evidence”, CGAP Focus Note, 92, https://www.cgap.org/sites/default/files/FocusNote-Financial-Inclusion-andDevelopment-April-2014.pdf, (23.10.2020).

De Koker, Louis - Jentzsch, Nicola (2013), “Financial Inclusion and Financial Integrity: Aligned Incentives?’’, World Development, 44, pp.267-280.

Demirguc-Kunt, Asli - Klapper, Leora - Singer, Dorothe - Ansar, Saniya - Hess, Jake (2018), "Global Findex Database 2017: Measuring Financial Inclusion and the Fintech Revolution’', Washington, DC: World Bank.

Demirguc-Kunt, Asli - Klapper, Leora - Singer, Dorothe - Van Oudheusden, Peter (2015), “Measuring Financial Inclusion Around the World”, World Bank Policy Research Working Paper 7255, http://documents1.worldbank.org/curated/en/ 187761468179367706/pdf/WPS7255.pdf, ( 02.11.2020).

Demirguc-Kunt, Asli - Beck, Thorsten - Honohan, Patrick (2008), “Finance for All? 
Policies and Pitfalls in Expanding Access”, World Bank, Washington DC.

Dev, Mahendra S. (2006), “Financial Inclusion: Issues and Challenges”, Economic and Political Weekly, 41, 41, pp.4310-4313.

Duncombe, Richard - Boateng, Richard (2009), "Mobile Phones and Financial Services in Developing Countries: A Review of Concepts, Methods, Issues, Evidence and Future Research Directions'”, Third World Quarterly, 30, 7, pp.1237-1258.

European Commission (2008), "Financial services provision and prevention of financial exclusion', https://www.fi-compass.eu/publication/other-resources/financial-servicesprovision-and-prevention-financial-exclusion, (16.11.2020).

Fungáčová, Zuzana - Weill, Laurent (2015), “Understanding Financial Inclusion in China’, China Economic Review, 34C, pp.196 - 206.

Ginevicius, Romualdas - Dudzeviciute, Gitana - Schieg, Martin - Peleckis, Kestutis (2019), "The Inter-Linkages Between Financial and Economic Development in The European Union Countries”, Economic Research-Ekonomska Istraživanja, 32, 1, pp.3309-3326.

Global Partnership for Financial Inclusion (2014), "Digital Financial Inclusion and The Implications for Customers, Regulators, Supervisors And Standard-Setting Bodies”, $\quad$ https://www.gpfi.org/publications/digital-financial-inclusion-andimplications-customers-regulators-supervisors-and-standard-setting, (12.11.2020).

Gupte, Rajani - Venkataramani, Bhama - Gupta, Deepa (2012). “Computation of Financial Inclusion Index for India”, Procedia - Social and Behavioral Sciences, 37, pp.133149.

Gündüz, Murat - Özyıldırım, Yunus (2019), “'Türkiye’de İllere Göre Finansal Kapsayıcılık Endeksinin Ölçülmesi’, Bankacılar, 111, ss.52-70.

Işık, İhsan, (2011), “Dünyada ve Türkiye’de Finansal Hizmetlere Erişim ve Finansal Eğitim’, Ankara: Türkiye Cumhuriyet Merkez Bankası.

Jeanneney, Sylviane G. - Kpodar, Kangni R. (2011), “Financial Development and Poverty Reduction: Can There Be A Benefit Without A Cost?’, The Journal of Development Studies, 47, 1, pp.143-163.

Kempson, Elaine - Atkinson, Adele - Pilley, Odile (2004), "Policy Level Response to Financial Exclusion in Developed Economies: Lessons for Developing Countries", Report of Personal Finance Research Centre, University of Bristol, Bristol. http://www.bristol.ac.uk/geography/research/pfrc/themes/finexc/policy-levelresponse.html, (26.10.2020).

Kim, Dai-Won, - Yu, Jung-Suk - Hassan, M. Kabir (2018), "Financial Inclusion and Economic Growth in OIC Countries”, Research in International Business and Finance, 43, pp.1-14. 
Kim, Jong-Hee (2016), “A Study on the Effect of Financial Inclusion on the Relationship Between Income Inequality and Economic Growth”, Emerging Markers Finance and Trade, 52, 2, pp. $1-15$.

Leyshon, Andrew - Thrift, Nigel (1995), "Geographies of Financial Exclusion: Financial Abandonment in Britain and The United States", Transactions of the Institute of British Geographers, 20, 3, 312-341.

Musabegovic, Ismail, - Özer, Mustafa - Djukovic, Sladana - Jovanovic, Stefan (2019), "Influence of Financial Technology (FINTECH) on Financial Industry", Economics of Agriculture, 66, 4, pp.1003-1021.

Nanda, Kajole (2017), “Bank Led Financial Inclusion and Socio Economic Development: The Case of Indian States”, Pacific Business Review International, 10, 4, pp.39-49.

Özsuca, Ekin A. (2019), "Gender Gap in Financial Inclusion: Evidence from MENA", Economics and Business Letters, 8, 4, pp.199-208.

Pal, Rupayan - Vaidya, Rajendra (2011), “Outreach of Banking Services Across Indian States: 1981-2007 Converging or Diverging?” In DM Nachane (ed.). India Development Report, pp.116-129.

Patwardhan, Anju - Singleton, Ken - Schmitz, Kai (2018), “Financial Inclusion in the Digital Age”, International Finance Corporation-Creditease-Stanford Graduate School of Business.

Rastogi, Shailesh - Ragabiruntha, Ellapan (2018), "Financial Inclusion and Socioeconomic Development: Gaps and Solution”, International Journal of Social Economics, 45, 7, 1122-1140.

Raza, Muhammad S. - Tang, Jun - Rubab, Sana - Wen, Xin (2019), “'Determining the Nexus Between Financial Inclusion and Economic Development in Pakistan”, Journal of Money Laundering Control, 22, 2, pp.195-209.

Sani, Ibrahim S. - Özdeşer, Hüseyin - Çavuşoğlu, Behiye (2019), "Financial Inclusion As A Pathway to Welfare Enhancement and Income Equality: Micro-Level Evidence from Nigeria”, Development Southern Africa, 36, 3, 390-407.

Sarıgül, Haşmet (2020). "The Determining Factors of Financial Inclusion in Turkey”, Journal of Economics Finance and Accounting, 7, 3, 223 - 235.

Sarma, Mandira - Pais, Jesim (2011), “Financial Inclusion and Development. International Journal of Development”, 23, pp.613-628.

Sarma, Mandira (2008), "Index of Financial Inclusion”, Indian Council for Research on International Economic Relations, New Delhi Working Papers 215.

Sethi, Dinabandhu - Acharya, Debashis (2018), "Financial Inclusion and Economic Growth Linkage: Some Cross Country Evidence”, Journal of Financial Economic Policy, 10, 
3, pp.369-385.

Sethi, Dinabandhu - Sethy, Susa K. (2018), "Financial Inclusion Matters for Economic Growth in India”, International Journal of Social Economics, 46, 1, pp.132-151.

Seven, Ünal - Yassa, Ahmet D. - Yılmaz, Fatih (2020), “Finansal Kapsayıcılık: Türkiye ve Dünya Karşılaştırması’, TCMB Ekonomi Notları, 2020-04.

Sha'bana, Mais - Girardone Claudia - Sarkisyan, Anna (2020), “Cross-Country Variation in Financial Inclusion: A Global Perspective’', The European Journal of Finance, 26, 45, pp.319- 340 .

Szopinski, Tomasz (2019), “Who is Unbanked? Evidence From Poland”, Contemporary Economics, 13, 4, pp.417-426.

T.C. Başbakanlık (2014), "Finansal Erişim, Finansal Eğitim, Tüketici Finansal Koruma Stratejisi ve Eylem Planları’, Resmi Gazete No. 29021.

Temizel, Fatih. - Bayçelebi, Berfu E. (2018), “Finansal Dışlanmışlık Analizi: Eskişehir’de Öğrenim Gören İktisadi ve İdari Bilimler Fakültesi (İIBF) Öğrencileri Üzerine Bir Araştırma', Uluslararası İşletme ve Yönetim Dergisi, 6, 4, ss.1152-1177.

World Bank (2018), “'New Report Analyses China’s Impressive Trajectory Toward Universal Financial Inclusion’’, https://www.worldbank.org/en/news/feature /2018/02/09/newreport-analyzes-china-impressive-trajectory-toward-universal-financial-inclusion (12.12.2020).

World Bank (2014), “Global Financial Development Report 2014: Financial Inclusion’, World Bank Publications. https://openknowledge.worldbank.org/handle/10986 /16238, (15.12.2020).

World Bank (2012), “Financial Inclusion Strategies Reference Framework”, http://documents1.worldbank.org/curated/en/801151468152092070/pdf/787610WP0P 144500use0only0900A9RD899.pdf, (17.06.2020).

Van, Loan T.H. - Vo, Anh T., - Nguyen, Nhan T. - Vo, Duc H. (2019), "Financial Inclusion and Economic Growth: An International Evidence”, Emerging Markets Finance Trade, Early Access, pp.239-263.

Van Der Werff, Andrew D., - Hogarth, Jeanne M. - Peach, Nathanael D. (2013), “A CrossCountry Analysis of Financial Inclusion within the OECD', Consumer Interests Annual, 59, pp.1-12.

Yorulmaz, Recep (2013), “Construction of a Regional Financial Inclusion Index in Turkey”, BDDK Bankacilık ve Finansal Piyasalar, 7, 1, ss.79-101.

Zhang, Quanda - Posso, Alberto (2019), “Thinking Inside the Box: A Closer Look at Financial Inclusion And Household Income’, The Journal of Development Studies, 55, 7, pp.1616-1631. 
EKLER

Ek 1. İllere Göre TFKE Tablosu

\begin{tabular}{|c|c|c|c|c|c|c|c|c|}
\hline & 2011 & 2012 & 2013 & 2014 & 2015 & 2016 & 2017 & 2018 \\
\hline Adana & 0,32 & 0,33 & 0,33 & 0,33 & 0,33 & 0,32 & 0,32 & 0,33 \\
\hline Adiyaman & 0,12 & 0,12 & 0,12 & 0,11 & 0,12 & 0,12 & 0,12 & 0,12 \\
\hline Afyonkarahisar & 0,26 & 0,26 & 0,27 & 0,27 & 0,27 & 0,28 & 0,29 & 0,29 \\
\hline Ağr1 & 0,05 & 0,05 & 0,06 & 0,06 & 0,06 & 0,06 & 0,06 & 0,06 \\
\hline Aksaray & 0,22 & 0,23 & 0,24 & 0,23 & 0,23 & 0,24 & 0,24 & 0,23 \\
\hline Amasya & 0,28 & 0,28 & 0,29 & 0,29 & 0,30 & 0,30 & 0,31 & 0,31 \\
\hline Ankara & 0,46 & 0,46 & 0,46 & 0,46 & 0,46 & 0,45 & 0,45 & 0,45 \\
\hline Antalya & 0,40 & 0,42 & 0,43 & 0,43 & 0,43 & 0,44 & 0,43 & 0,42 \\
\hline Ardahan & 0,19 & 0,18 & 0,22 & 0,23 & 0,21 & 0,23 & 0,25 & 0,26 \\
\hline Artvin & 0,34 & 0,34 & 0,34 & 0,35 & 0,35 & 0,35 & 0,36 & 0,35 \\
\hline Aydın & 0,39 & 0,40 & 0,40 & 0,41 & 0,41 & 0,42 & 0,42 & 0,42 \\
\hline Balıkesir & 0,34 & 0,35 & 0,35 & 0,35 & 0,36 & 0,36 & 0,36 & 0,36 \\
\hline Bartın & 0,33 & 0,33 & 0,34 & 0,34 & 0,34 & 0,34 & 0,35 & 0,35 \\
\hline Batman & 0,07 & 0,08 & 0,08 & 0,08 & 0,08 & 0,08 & 0,08 & 0,07 \\
\hline Bayburt & 0,21 & 0,22 & 0,22 & 0,21 & 0,22 & 0,19 & 0,21 & 0,20 \\
\hline Bilecik & 0,26 & 0,27 & 0,27 & 0,27 & 0,27 & 0,26 & 0,27 & 0,27 \\
\hline Bingöl & 0,06 & 0,07 & 0,07 & 0,07 & 0,07 & 0,08 & 0,08 & 0,08 \\
\hline Bitlis & 0,09 & 0,08 & 0,08 & 0,08 & 0,09 & 0,09 & 0,10 & 0,10 \\
\hline Bolu & 0,27 & 0,28 & 0,28 & 0,28 & 0,28 & 0,28 & 0,29 & 0,28 \\
\hline Burdur & 0,31 & 0,32 & 0,32 & 0,31 & 0,31 & 0,32 & 0,33 & 0,34 \\
\hline Bursa & 0,32 & 0,33 & 0,32 & 0,33 & 0,33 & 0,34 & 0,34 & 0,33 \\
\hline Çanakkale & 0,31 & 0,32 & 0,32 & 0,33 & 0,34 & 0,34 & 0,34 & 0,33 \\
\hline Çankırı & 0,26 & 0,25 & 0,25 & 0,27 & 0,27 & 0,28 & 0,29 & 0,27 \\
\hline Çorum & 0,28 & 0,29 & 0,29 & 0,29 & 0,29 & 0,29 & 0,29 & 0,30 \\
\hline Denizli & 0,33 & 0,33 & 0,35 & 0,35 & 0,36 & 0,36 & 0,36 & 0,36 \\
\hline Diyarbakır & 0,11 & 0,11 & 0,12 & 0,12 & 0,12 & 0,12 & 0,12 & 0,12 \\
\hline Düzce & 0,24 & 0,25 & 0,26 & 0,25 & 0,24 & 0,25 & 0,25 & 0,26 \\
\hline Edirne & 0,37 & 0,38 & 0,39 & 0,39 & 0,40 & 0,40 & 0,40 & 0,41 \\
\hline Elazığ & 0,19 & 0,20 & 0,20 & 0,21 & 0,21 & 0,21 & 0,21 & 0,21 \\
\hline Erzincan & 0,24 & 0,24 & 0,26 & 0,26 & 0,27 & 0,27 & 0,26 & 0,26 \\
\hline Erzurum & 0,18 & 0,18 & 0,19 & 0,19 & 0,19 & 0,19 & 0,19 & 0,19 \\
\hline Eskişehir & 0,32 & 0,33 & 0,34 & 0,35 & 0,35 & 0,35 & 0,36 & 0,35 \\
\hline Gaziantep & 0,19 & 0,20 & 0,21 & 0,21 & 0,20 & 0,20 & 0,21 & 0,20 \\
\hline Giresun & 0,33 & 0,33 & 0,33 & 0,33 & 0,32 & 0,33 & 0,34 & 0,34 \\
\hline Gümüşhane & 0,19 & 0,19 & 0,21 & 0,20 & 0,19 & 0,18 & 0,18 & 0,19 \\
\hline Hakkari & 0,05 & 0,05 & 0,06 & 0,07 & 0,08 & 0,09 & 0,09 & 0,09 \\
\hline Hatay & 0,24 & 0,25 & 0,26 & 0,26 & 0,25 & 0,25 & 0,24 & 0,23 \\
\hline Iğdır & 0,13 & 0,13 & 0,14 & 0,17 & 0,15 & 0,16 & 0,15 & 0,15 \\
\hline Isparta & 0,33 & 0,33 & 0,34 & 0,34 & 0,34 & 0,34 & 0,34 & 0,34 \\
\hline İstanbul & 0,75 & 0,76 & 0,77 & 0,77 & 0,76 & 0,75 & 0,72 & 0,71 \\
\hline İzmir & 0,46 & 0,46 & 0,46 & 0,47 & 0,47 & 0,47 & 0,46 & 0,46 \\
\hline Kahramanmaraş & 0,12 & 0,13 & 0,15 & 0,15 & 0,15 & 0,16 & 0,16 & 0,16 \\
\hline Karabük & 0,31 & 0,34 & 0,33 & 0,34 & 0,34 & 0,33 & 0,35 & 0,33 \\
\hline Karaman & 0,24 & 0,23 & 0,25 & 0,24 & 0,24 & 0,25 & 0,24 & 0,25 \\
\hline Kars & 0,17 & 0,17 & 0,18 & 0,19 & 0,18 & 0,18 & 0,20 & 0,20 \\
\hline Kastamonu & 0,29 & 0,30 & 0,29 & 0,30 & 0,30 & 0,29 & 0,30 & 0,30 \\
\hline Kayseri & 0,26 & 0,27 & 0,28 & 0,28 & 0,29 & 0,30 & 0,30 & 0,30 \\
\hline Kırıkkale & 0,24 & 0,25 & 0,26 & 0,27 & 0,27 & 0,27 & 0,26 & 0,26 \\
\hline Kırklareli & 0,33 & 0,33 & 0,35 & 0,35 & 0,36 & 0,36 & 0,36 & 0,35 \\
\hline Kırşehir & 0,28 & 0,31 & 0,32 & 0,33 & 0,33 & 0,32 & 0,32 & 0,31 \\
\hline
\end{tabular}




\begin{tabular}{lllllllll} 
Kilis & 0,16 & 0,17 & 0,15 & 0,21 & 0,16 & 0,18 & 0,17 & 0,17 \\
Kocaeli & 0,31 & 0,31 & 0,31 & 0,30 & 0,30 & 0,31 & 0,29 & 0,28 \\
Konya & 0,23 & 0,24 & 0,24 & 0,23 & 0,23 & 0,23 & 0,23 & 0,23 \\
Kütahya & 0,24 & 0,25 & 0,26 & 0,26 & 0,27 & 0,27 & 0,27 & 0,26 \\
Malatya & 0,20 & 0,21 & 0,23 & 0,24 & 0,23 & 0,23 & 0,23 & 0,23 \\
Manisa & 0,26 & 0,25 & 0,27 & 0,27 & 0,28 & 0,28 & 0,28 & 0,28 \\
Mardin & 0,06 & 0,07 & 0,07 & 0,06 & 0,06 & 0,07 & 0,06 & 0,05 \\
Mersin & 0,29 & 0,29 & 0,30 & 0,30 & 0,30 & 0,30 & 0,30 & 0,30 \\
Muğla & 0,46 & 0,46 & 0,47 & 0,47 & 0,47 & 0,47 & 0,47 & 0,47 \\
Muş & 0,01 & 0,01 & 0,01 & 0,01 & 0,01 & 0,03 & 0,02 & 0,02 \\
Nevşehir & 0,32 & 0,34 & 0,35 & 0,35 & 0,35 & 0,34 & 0,35 & 0,35 \\
Niğde & 0,19 & 0,19 & 0,20 & 0,19 & 0,19 & 0,20 & 0,20 & 0,19 \\
Ordu & 0,26 & 0,26 & 0,26 & 0,27 & 0,25 & 0,26 & 0,27 & 0,27 \\
Osmaniye & 0,14 & 0,16 & 0,17 & 0,16 & 0,17 & 0,17 & 0,17 & 0,16 \\
Rize & 0,32 & 0,32 & 0,32 & 0,31 & 0,32 & 0,32 & 0,32 & 0,31 \\
Sakarya & 0,25 & 0,26 & 0,27 & 0,26 & 0,26 & 0,27 & 0,27 & 0,26 \\
Samsun & 0,28 & 0,28 & 0,29 & 0,30 & 0,29 & 0,30 & 0,30 & 0,30 \\
Siirt & 0,07 & 0,08 & 0,08 & 0,08 & 0,09 & 0,08 & 0,08 & 0,08 \\
Sinop & 0,30 & 0,31 & 0,31 & 0,31 & 0,32 & 0,32 & 0,33 & 0,33 \\
Sivas & 0,24 & 0,25 & 0,26 & 0,26 & 0,26 & 0,27 & 0,28 & 0,27 \\
Şanliurfa & 0,05 & 0,06 & 0,06 & 0,06 & 0,05 & 0,06 & 0,05 & 0,05 \\
Şırnak & 0,03 & 0,02 & 0,03 & 0,03 & 0,01 & 0,01 & 0,01 & 0,01 \\
Tekirdağ & 0,31 & 0,31 & 0,33 & 0,33 & 0,32 & 0,32 & 0,31 & 0,31 \\
Tokat & 0,24 & 0,24 & 0,24 & 0,25 & 0,24 & 0,24 & 0,24 & 0,25 \\
Trabzon & 0,34 & 0,34 & 0,35 & 0,34 & 0,34 & 0,35 & 0,34 & 0,34 \\
Tunceli & 0,35 & 0,32 & 0,34 & 0,36 & 0,36 & 0,35 & 0,35 & 0,34 \\
Uşak & 0,31 & 0,31 & 0,33 & 0,32 & 0,33 & 0,32 & 0,33 & 0,33 \\
Van & 0,07 & 0,06 & 0,06 & 0,06 & 0,07 & 0,07 & 0,08 & 0,08 \\
Yalova & 0,37 & 0,38 & 0,38 & 0,38 & 0,38 & 0,38 & 0,37 & 0,35 \\
Yozgat & 0,23 & 0,24 & 0,26 & 0,26 & 0,26 & 0,27 & 0,29 & 0,29 \\
Zonguldak & 0,36 & 0,37 & 0,37 & 0,37 & 0,37 & 0,37 & 0,37 & 0,36 \\
\hline
\end{tabular}


Ek 2. İllerin TFKE Düzeylerinin Belirlenmesinde Esas Alınan Değerler Tablosu

\begin{tabular}{llllll}
\hline 2011 & $0.000 \leq d 5<0.100$ & $0.100 \leq d 4<0.200$ & $0.200 \leq d 3<0.400$ & $0.400 \leq d 2<0.700$ & $0.700 \leq d 1 \leq 1$ \\
2012 & $0.000 \leq d 5<0.102$ & $0.102 \leq d 4<0.205$ & $0.205 \leq d 3<0.405$ & $0.405 \leq d 2<0.702$ & $0.702 \leq d 1 \leq 1$ \\
2013 & $0.000 \leq d 5<0.105$ & $0.105 \leq d 4<0.211$ & $0.211 \leq d 3<0.411$ & $0.411 \leq d 2<0.705$ & $0.705 \leq d 1 \leq 1$ \\
2014 & $0.000 \leq d 5<0.106$ & $0.106 \leq d 4<0.212$ & $0.212 \leq d 3<0.412$ & $0.412 \leq d 2<0.706$ & $0.706 \leq d 1 \leq 1$ \\
2015 & $0.000 \leq d 5<0.105$ & $0.105 \leq d 4<0.211$ & $0.211 \leq d 3<0.411$ & $0.411 \leq d 2<0.705$ & $0.705 \leq d 1 \leq 1$ \\
2016 & $0.000 \leq d 5<0.106$ & $0.106 \leq d 4<0.212$ & $0.212 \leq d 3<0.412$ & $0.412 \leq d 2<0.706$ & $0.706 \leq d 1 \leq 1$ \\
2017 & $0.000 \leq d 5<0.107$ & $0.107 \leq d 4<0.213$ & $0.213 \leq d 3<0.413$ & $0.413 \leq d 2<0.707$ & $0.707 \leq d 1 \leq 1$ \\
2018 & $0.000 \leq d 5<0.106$ & $0.106 \leq d 4<0.212$ & $0.212 \leq d 3<0.412$ & $0.412 \leq d 2<0.706$ & $0.706 \leq d 1 \leq 1$ \\
\hline
\end{tabular}

$d 5$ : çok düşük, $d 4$ : düşük, $d 3$ : orta, $d 2$ : yüksek, $d 1$ : çok yüksek düzeyde finansal kapsayıcılığı göstermektedir.

Ek 3. İllerin Finansal Kapsayıcılık Düzeyleri Tablosu

\begin{tabular}{|c|c|c|c|c|c|c|c|c|}
\hline & 2011 & 2012 & 2013 & 2014 & 2015 & 2016 & 2017 & 2018 \\
\hline Adana & $d 3$ & $d 3$ & $d 3$ & $d 3$ & $d 3$ & $d 3$ & $d 3$ & $d 3$ \\
\hline Adiyaman & $d 4$ & $d 4$ & $d 4$ & $d 4$ & $d 4$ & $d 4$ & $d 4$ & $d 4$ \\
\hline Afyonkarahisar & $d 3$ & d3 & $d 3$ & $d 3$ & $d 3$ & $d 3$ & $d 3$ & $d 3$ \\
\hline Ağr1 & $d 5$ & $d 5$ & $d 5$ & $d 5$ & $d 5$ & $d 5$ & $d 5$ & $d 5$ \\
\hline Aksaray & $d 3$ & $d 3$ & $d 3$ & $d 3$ & $d 3$ & $d 3$ & $d 3$ & $d 3$ \\
\hline Amasya & $d 3$ & $d 3$ & $d 3$ & $d 3$ & $d 3$ & $d 3$ & $d 3$ & $d 3$ \\
\hline Ankara & $d 2$ & $d 2$ & $d 2$ & $d 2$ & $d 2$ & $d 2$ & $d 2$ & $d 2$ \\
\hline Antalya & $d 2$ & $d 2$ & $d 2$ & $d 2$ & $d 2$ & $d 2$ & $d 2$ & $d 2$ \\
\hline Ardahan & $d 4$ & $d 4$ & $d 3$ & $d 3$ & $d 3$ & $d 3$ & $d 3$ & $d 3$ \\
\hline Artvin & $d 3$ & d3 & $d 3$ & $d 3$ & $d 3$ & $d 3$ & $d 3$ & $d 3$ \\
\hline Aydin & $d 3$ & $d 3$ & $d 3$ & $d 3$ & $d 2$ & $d 2$ & $d 2$ & $d 2$ \\
\hline Balıkesir & $d 3$ & $d 3$ & $d 3$ & $d 3$ & $d 3$ & $d 3$ & $d 3$ & $d 3$ \\
\hline Bartın & $d 3$ & $d 3$ & $d 3$ & $d 3$ & $d 3$ & $d 3$ & $d 3$ & $d 3$ \\
\hline Batman & $d 5$ & $d 5$ & d5 & $d 5$ & $d 5$ & $d 5$ & d5 & $d 5$ \\
\hline Bayburt & $d 3$ & d3 & $d 3$ & $d 3$ & $d 3$ & $d 4$ & $d 3$ & $d 3$ \\
\hline Bilecik & $d 3$ & $d 3$ & $d 3$ & $d 3$ & $d 3$ & $d 3$ & $d 3$ & $d 3$ \\
\hline Bingöl & $d 5$ & $d 5$ & $d 5$ & $d 5$ & $d 5$ & $d 5$ & $d 5$ & $d 5$ \\
\hline Bitlis & $d 5$ & d5 & d5 & d5 & $d 5$ & $d 5$ & d5 & $d 5$ \\
\hline Bolu & $d 3$ & d3 & $d 3$ & $d 3$ & $d 3$ & $d 3$ & $d 3$ & $d 3$ \\
\hline Burdur & $d 3$ & $d 3$ & $d 3$ & $d 3$ & $d 3$ & $d 3$ & $d 3$ & $d 3$ \\
\hline Bursa & $d 3$ & $d 3$ & $d 3$ & $d 3$ & $d 3$ & $d 3$ & $d 3$ & $d 3$ \\
\hline Çanakkale & $d 3$ & $d 3$ & $d 3$ & $d 3$ & $d 3$ & $d 3$ & $d 3$ & $d 3$ \\
\hline Çankırı & $d 3$ & d3 & $d 3$ & $d 3$ & $d 3$ & $d 3$ & $d 3$ & $d 3$ \\
\hline Çorum & $d 3$ & $d 3$ & $d 3$ & $d 3$ & $d 3$ & $d 3$ & $d 3$ & $d 3$ \\
\hline Denizli & $d 3$ & d3 & $d 3$ & $d 3$ & $d 3$ & $d 3$ & $d 3$ & $d 3$ \\
\hline Diyarbakır & $d 4$ & $d 4$ & $d 4$ & $d 4$ & $d 4$ & $d 4$ & $d 4$ & $d 4$ \\
\hline Düzce & $d 3$ & d3 & $d 3$ & $d 3$ & $d 3$ & $d 3$ & $d 3$ & $d 3$ \\
\hline Edirne & $d 3$ & $d 3$ & $d 3$ & $d 3$ & $d 3$ & $d 3$ & $d 3$ & $d 3$ \\
\hline Elazı̆̆ & $d 4$ & $d 4$ & $d 4$ & $d 4$ & $d 4$ & $d 4$ & $d 4$ & $d 4$ \\
\hline Erzincan & $d 3$ & $d 3$ & $d 3$ & $d 3$ & $d 3$ & $d 3$ & $d 3$ & $d 3$ \\
\hline Erzurum & $d 4$ & $d 4$ & $d 4$ & $d 4$ & $d 4$ & $d 4$ & $d 4$ & $d 4$ \\
\hline Eskişehir & $d 3$ & $d 3$ & $d 3$ & $d 3$ & $d 3$ & $d 3$ & $d 3$ & $d 3$ \\
\hline Gaziantep & $d 4$ & $d 4$ & $d 4$ & $d 4$ & $d 4$ & $d 4$ & $d 4$ & $d 4$ \\
\hline Giresun & $d 3$ & $d 3$ & $d 3$ & $d 3$ & $d 3$ & $d 3$ & $d 3$ & $d 3$ \\
\hline Gümüşhane & $d 4$ & $d 4$ & $d 4$ & $d 4$ & $d 4$ & $d 4$ & $d 4$ & $d 4$ \\
\hline Hakkari & $d 5$ & $d 5$ & $d 5$ & $d 5$ & $d 5$ & $d 5$ & $d 5$ & $d 5$ \\
\hline
\end{tabular}




\begin{tabular}{|c|c|c|c|c|c|c|c|c|}
\hline Hatay & $d 3$ & $d 3$ & $d 3$ & $d 3$ & $d 3$ & $d 3$ & $d 3$ & $d 3$ \\
\hline Iğdır & $d 4$ & $d 4$ & $d 4$ & $d 4$ & $d 4$ & $d 4$ & $d 4$ & $d 4$ \\
\hline Isparta & $d 3$ & $d 3$ & $d 3$ & $d 3$ & $d 3$ & $d 3$ & $d 3$ & $d 3$ \\
\hline İstanbul & $d 1$ & $d 1$ & $d 1$ & $d 1$ & $d 1$ & $d 1$ & $d 1$ & $d 1$ \\
\hline İzmir & $d 2$ & $d 2$ & $d 2$ & $d 2$ & $d 2$ & $d 2$ & $d 2$ & $d 2$ \\
\hline Kahramanmaraş & $d 4$ & $d 4$ & $d 4$ & $d 4$ & $d 4$ & $d 4$ & $d 4$ & $d 4$ \\
\hline Karabük & $d 3$ & $d 3$ & $d 3$ & $d 3$ & $d 3$ & $d 3$ & $d 3$ & $d 3$ \\
\hline Karaman & $d 3$ & $d 3$ & $d 3$ & $d 3$ & $d 3$ & $d 3$ & $d 3$ & $d 3$ \\
\hline Kars & $d 4$ & $d 4$ & $d 4$ & $d 4$ & $d 4$ & $d 4$ & $d 4$ & $d 4$ \\
\hline Kastamonu & $d 3$ & $d 3$ & $d 3$ & $d 3$ & $d 3$ & $d 3$ & $d 3$ & $d 3$ \\
\hline Kayseri & $d 3$ & $d 3$ & $d 3$ & $d 3$ & $d 3$ & $d 3$ & $d 3$ & $d 3$ \\
\hline Kilis & $d 4$ & $d 4$ & $d 4$ & $d 4$ & $d 4$ & $d 4$ & $d 4$ & $d 4$ \\
\hline Kırıkkale & $d 3$ & $d 3$ & $d 3$ & $d 3$ & $d 3$ & $d 3$ & $d 3$ & $d 3$ \\
\hline Kırklareli & $d 3$ & $d 3$ & $d 3$ & $d 3$ & $d 3$ & $d 3$ & $d 3$ & $d 3$ \\
\hline Kırşehir & $d 3$ & $d 3$ & $d 3$ & $d 3$ & $d 3$ & $d 3$ & $d 3$ & $d 3$ \\
\hline Kocaeli & $d 3$ & $d 3$ & $d 3$ & $d 3$ & $d 3$ & $d 3$ & $d 3$ & $d 3$ \\
\hline Konya & $d 3$ & $d 3$ & $d 3$ & $d 3$ & $d 3$ & $d 3$ & $d 3$ & $d 3$ \\
\hline Kütahya & $d 3$ & $d 3$ & $d 3$ & $d 3$ & $d 3$ & $d 3$ & $d 3$ & $d 3$ \\
\hline Malatya & $d 3$ & $d 3$ & $d 3$ & $d 3$ & $d 3$ & $d 3$ & $d 3$ & $d 3$ \\
\hline Manisa & $d 3$ & $d 3$ & $d 3$ & $d 3$ & $d 3$ & $d 3$ & $d 3$ & $d 3$ \\
\hline Mardin & $d 5$ & $d 5$ & $d 5$ & $d 5$ & $d 5$ & $d 5$ & $d 5$ & $d 5$ \\
\hline Mersin & $d 3$ & $d 3$ & $d 3$ & $d 3$ & $d 3$ & $d 3$ & $d 3$ & $d 3$ \\
\hline Muğla & $d 2$ & $d 2$ & $d 2$ & $d 2$ & $d 2$ & $d 2$ & $d 2$ & $d 2$ \\
\hline Muş & $d 5$ & $d 5$ & $d 5$ & $d 5$ & $d 5$ & $d 5$ & $d 5$ & $d 5$ \\
\hline Nevşehir & $d 3$ & $d 3$ & $d 3$ & $d 3$ & $d 3$ & $d 3$ & $d 3$ & $d 3$ \\
\hline Niğde & $d 4$ & $d 4$ & $d 4$ & $d 4$ & $d 4$ & $d 4$ & $d 4$ & $d 4$ \\
\hline Ordu & $d 3$ & $d 3$ & $d 3$ & $d 3$ & $d 3$ & $d 3$ & $d 3$ & $d 3$ \\
\hline Osmaniye & $d 4$ & $d 4$ & $d 4$ & $d 4$ & $d 4$ & $d 4$ & $d 4$ & $d 4$ \\
\hline Rize & $d 3$ & $d 3$ & $d 3$ & $d 3$ & $d 3$ & $d 3$ & $d 3$ & $d 3$ \\
\hline Sakarya & $d 3$ & $d 3$ & $d 3$ & $d 3$ & $d 3$ & $d 3$ & $d 3$ & $d 3$ \\
\hline Samsun & $d 3$ & $d 3$ & $d 3$ & $d 3$ & $d 3$ & $d 3$ & $d 3$ & $d 3$ \\
\hline Şanlıurfa & $d 5$ & $d 5$ & $d 5$ & $d 5$ & $d 5$ & $d 5$ & $d 5$ & $d 5$ \\
\hline Siirt & $d 5$ & $d 5$ & $d 5$ & $d 5$ & $d 5$ & $d 5$ & $d 5$ & $d 5$ \\
\hline Sinop & $d 3$ & $d 3$ & $d 3$ & $d 3$ & $d 3$ & $d 3$ & $d 3$ & $d 3$ \\
\hline Şırnak & $d 5$ & $d 5$ & $d 5$ & $d 5$ & $d 5$ & $d 5$ & $d 5$ & $d 5$ \\
\hline Sivas & $d 3$ & $d 3$ & $d 3$ & $d 3$ & $d 3$ & $d 3$ & $d 3$ & $d 3$ \\
\hline Tekirdağ & $d 3$ & $d 3$ & $d 3$ & $d 3$ & $d 3$ & $d 3$ & $d 3$ & $d 3$ \\
\hline Tokat & $d 3$ & $d 3$ & $d 3$ & $d 3$ & $d 3$ & $d 3$ & $d 3$ & $d 3$ \\
\hline Trabzon & $d 3$ & $d 3$ & $d 3$ & $d 3$ & $d 3$ & $d 3$ & $d 3$ & $d 3$ \\
\hline Tunceli & $d 3$ & $d 3$ & $d 3$ & $d 3$ & $d 3$ & $d 3$ & $d 3$ & $d 3$ \\
\hline Uşak & $d 3$ & $d 3$ & $d 3$ & $d 3$ & $d 3$ & $d 3$ & $d 3$ & $d 3$ \\
\hline Van & $d 5$ & $d 5$ & $d 5$ & $d 5$ & $d 5$ & $d 5$ & $d 5$ & $d 5$ \\
\hline Yalova & $d 3$ & $d 3$ & $d 3$ & $d 3$ & $d 3$ & $d 3$ & $d 3$ & $d 3$ \\
\hline Yozgat & $d 3$ & $d 3$ & $d 3$ & $d 3$ & $d 3$ & $d 3$ & $d 3$ & $d 3$ \\
\hline Zonguldak & $d 3$ & $d 3$ & $d 3$ & $d 3$ & $d 3$ & $d 3$ & $d 3$ & $d 3$ \\
\hline
\end{tabular}

$d 5$ : çok düşük, $d 4$ : düşük, $d 3$ : orta, $d 2$ : yüksek, $d 1$ : çok yüksek düzeyde finansal kapsayıc1llğ̆ı göstermektedir. 
